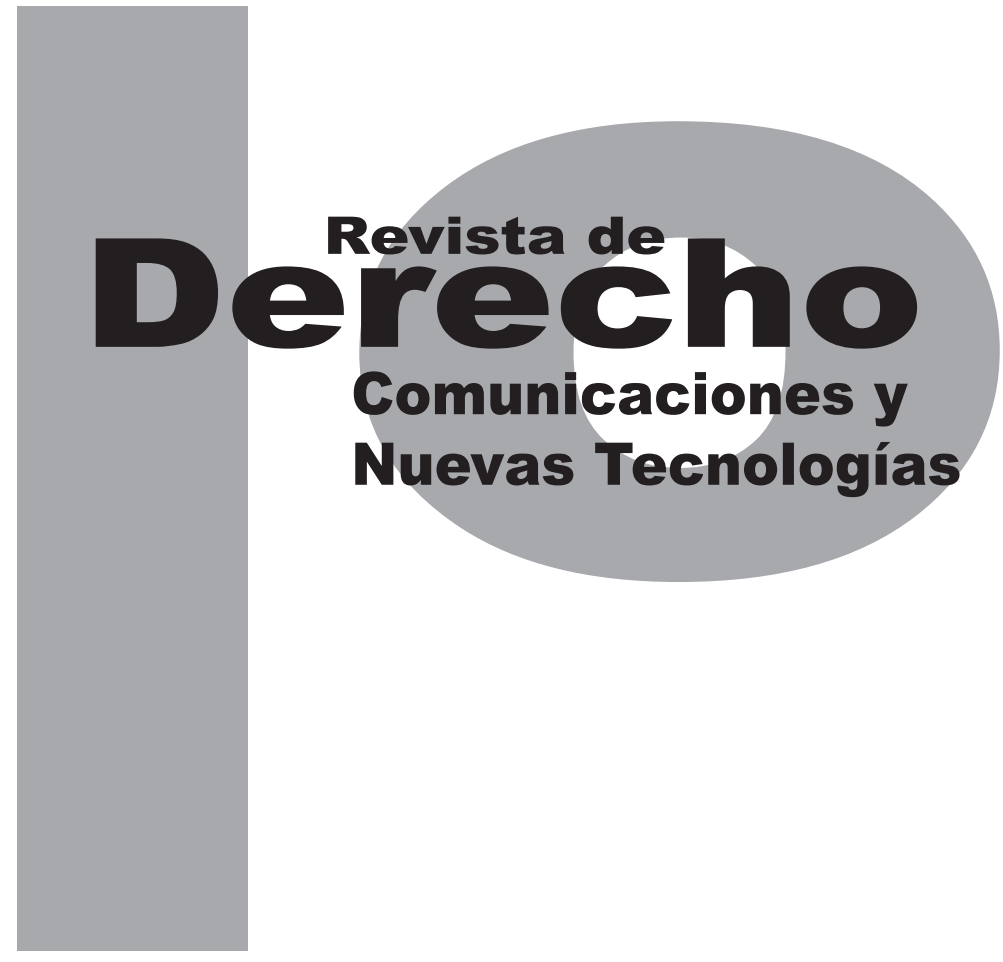

\title{
LA PROTECCIÓN DE DATOS EN EL ENTORNO LABORAL
}

\author{
María del Rosario Rivera SANClemente
}

Universidad de los Andes

Facultad de Derecho

Revista de Derecho, comunicaciones y Nuevas Tecnologías

N. ${ }^{\circ}$ 7, Junio de 2012. ISSN 1909-7786 


\title{
La protección de datos en el entorno laboral
}

\author{
María del Rosario Rivera Sanclemente ${ }^{1}$
}

\section{RESUMEN}

La legislación reconoce el derecho a la libertad informática, por constituir garantía de otros derechos como el honor y la intimidad, y por tratarse de un derecho autónomo que protege a las personas frente al uso indebido de la informática. En la relación de trabajo estos derechos exigen la comprensión y aplicación de una conducta profundamente ética, dejando de manifiesto la grandeza de la condición humana en la actividad social más importante de los seres humanos: el trabajo. Es evidente el poder de los empresarios sobre espacios no solo laborales sino también personalísimos del trabajador, amparados en la necesidad de control sobre la actividad productiva, lo cual obliga a los protagonistas del contrato de trabajo a una garantía recíproca en la protección y manejo de la información.

Palabras clave: protección de datos personales y privacidad, derecho informático, seguridad informática, derecho a la intimidad en el entorno laboral, contratación y medios electrónicos, derechos fundamentales del trabajador, autodeterminación informativa, habeas data, teletrabajo.
The legislation recognizes the right to freedom computing, for a guarantee of other rights such as privacy and honour because it is an unique and autonomous right that protects people against misuse of information. In the employment relationship these rights require the understanding and application of a profoundly ethical conduct, showing the greatness of the human condition in the people most important social activity: employment. It is obvious the power of entrepreneurs not only in working aspects but also very personal, protected by the need for control over productive activities, forcing the characters of the employment contract to a reciprocal guarantee in the protection and management of information.

Keywords: Privacy and Personal Data Protection, Computer Law, Computer Security, Right to Privacy in the Workplace, Procurement and Electronic Media, Fundamental Rights of Workers, Informational Self-determination, Habeas Data y Telework.

1 Ph.D (c). Derecho Universidad Carlos III de Madrid-España. Abogada Universidad de San Buenaventura, Cali-Colombia. Especialista en Derecho Administrativo, Universidad del Cauca-Colombia. Máster en Derecho Privado, Universidad Carlos III de Madrid; máster en Derecho de los Negocios y Litigación Internacional, Universidad Rey Juan Carlos, Madrid; máster en Negocio y Derecho de la Energía, Fundación Cremades \& Calvo Sotelo - Repsol YPF, Endesa y Enagás. Abogada Departamento Laboral, Mercantil y Comercio Electrónico, Madrid-España. Correo electrónico: rosario.riverasan@hotmail.com 


\section{SUMARIO}

Introducción - I. LA PROTECCIÓN DE DATOS EN EL ENTORNO LABORAL - II. EVOLUCIÓN HISTÓRICA - III. EL CONTRATO DE TRABAJO Y LOS DERECHOS FUNDAMENTALES - 3.1. Derecho a la intimidad, privacidad y autodeterminación informativa en España - 3.2. Derecho a la propia imagen - 3.3. Derecho a la no discriminación - 3.4. Derecho a la libertad de expresión e información - 3.5 Derecho a la libertad ideológica - 3.6. Derecho a la tutela judicial y garantía de indemnidad - 3.7. Derecho a la protección de datos de carácter personal - IV. EL ENTORNO LABORAL EN LA RELACIÓN DE TRABAJO - 4.1. Aspectos del entorno laboral - 4.2. Procedimientos de control de vigilancia - 4.3. Deber de la buena fe contractual - V. PRINCIPIOS QUE DIRECCIONAN LA ACTUACIÓN FRENTE A LA PROTECCIÓN DE DATOS - 5.1. Consentimiento informado - 5.2. Pertinencia y proporcionalidad - 5.3. Congruencia, finalidad y racionalidad - 5.4. Negociación colectiva - VI. INCIDENCIA DE LAS TIC Y EL CONTROL EMPRESARIAL - VII. CONCLUSIONES - Bibliografía. 


\section{INTRODUCCIÓN}

La necesidad de garantizar seguridad o protección a los datos de carácter personal recabados por las empresas y empleadores en los centros de trabajo, oficinas de Talento Humano y otras similares, constituye una preocupación permanente en las instituciones nacionales e internacionales por amenazar el equilibrio entre la seguridad y la libertad; preocupación que ha llevado a que el Comité Económico y Social de la Unión Europea afirme que "La cultura de la seguridad debe concebirse de manera plenamente compatible con la libertad de información, comunicación y expresión, las libertades económicas, sociales y culturales, y en general todos los derechos de la persona humana"2. Preocupan igualmente los diversos enfoques legislativos en varios países durante los últimos años. Las transacciones internacionales de datos se han incrementado notablemente y uno de sus objetivos principales es interaccionar la totalidad de los ordenadores de todas las instituciones, en principio públicas, para ir conociendo e integrando toda la información, lo que a juicio de muchos constituye una regresión en las libertades individuales y colectivas. Funcionarios de la Comisión de Libertades e Informática española han advertido sobre muchos abusos de poder, con sistemas a escala muy pequeña amparados en una "falsa seguridad", lo que a futuro se proyecta en proporciones gigantescas e incontrolables en detrimento de las libertades y derechos ciudadanos. Existe igualmente la certeza de que las tecnologías especialmente destinadas

2 Farriols, S. (2006). La protección de datos de carácter personal en los centros de trabajo. Madrid: Cinca S.A. a potenciar las comunicaciones, están aplicándose cada vez más al control de la ciudadanía y en especial de los trabajadores. La Constitución española en su art. 18.4 establece como un elemento fundamental, que la ley limitará el uso de la informática para proteger el honor y la intimidad personal y familiar de los ciudadanos, y el art. 4 del Estatuto de los Trabajadores (ET) regula el derecho a la intimidad de los propios datos personales.

Actualmente, la disponibilidad de herramientas para el manejo de datos personales y la naturaleza del trabajo han venido en constante transformación y cada una de ellas contribuye, de manera particular, a la cuestión de la confidencialidad de información personal en el trabajo, lo que justifica la necesidad de un marco jurídico donde se regulen las garantías necesarias para que el asalariado no ponga más que su fuerza laboral (y no su persona) a disposición del empleador, como lo afirma Bouchet Hubert, quien cita al profesor Rivero, cuando expresa que "Mediante el contrato el asalariado pone a disposición del empleador su fuerza de trabajo mas no su persona". ${ }^{3}$

La protección de datos en el entorno laboral aborda una serie de derechos en conflicto, que en ámbitos estrictamente privados no tendrían relevancia jurídica, pero sí pueden tenerla en el ambiente laboral en la medida en que la regulación jurídica de dicha relación debe respetar de igual forma los derechos fundamentales del

3 Bouchet, $\mathrm{H}$. De la confidencialidad de los datos personales en los lugares de trabajo. Traducción de Rosa Madrid Murcia. En Farriols, S. (2006). La protección de datos de carácter personal en los centros de trabajo. Madrid: Cinca S.A., pág. 169 y ss. 
trabajador como los del empleador o empresario, especialmente los de contenido constitucional. Es precisamente en la empresa, lugar de desarrollo de la actividad laboral, en donde pueden producirse intromisiones no legítimas en el derecho a la intimidad de los trabajadores por parte del empresario, cuando actúa con las posibilidades de control que la normativa le concede.

La conceptualización de los derechos fundamentales del ciudadano-trabajador en la relación laboral exige la compresión y aplicación de unos principios rectores en esta compleja relación filosófico-jurídica, que así mismo demanda el ejercicio de una conducta profundamente ética de unos y otros, dejando de manifiesto la grandeza de la condición humana en la actividad social más importante de los seres humanos: el trabajo.

Se describe e ilustra de igual manera el escenario de la relación laboral, que pone de manifiesto los alcances del poder de control de los empresarios o empleadores sobre espacios no sólo laborales, sino también personalísimos ${ }^{4}$ del trabajador, amparados en la necesidad de control de la organización sobre la actividad productiva en poder de los trabajadores, lo que obliga a los protagonistas del contrato de trabajo a una garantía recíproca en la protección y

4 Personalísimos, o de la persona. Son aquellos derechos morales que existen por fuera del patrimonio y se generan por el solo hecho de ser persona: derechos individuales, tales como la vida, la honra, el nombre, la libertad, la igualdad, la integridad física; o los derechos políticos. Son derechos que existen y están vigentes y disponibles durante toda la vida del sujeto; no son susceptibles de adquirirse o enajenarse; no son elementos de intercambio; no dependen de la voluntad. Son intransferibles, irrenunciables, imprescriptibles e inexpropiables. Casi todos ellos nacen y se extinguen ope legis con la persona. Disponible en www.mya.com.co/Derechospersonalisimos. manejo de la información que cada uno aporta en este tipo de transacción. Esto es, uso de las herramientas tecnológicas como ordenadores, Internet, correo electrónico, medios de vigilancia, bases de datos, etc. Paralelamente, se ilustra la normativa nacional e internacional vigente, propia de los distintos eventos y necesidades de aplicación.

\section{LA PROTECCIÓN DE DATOS EN EL ENTORNO LABORAL}

\begin{abstract}
"Porque todos somos celosos guardianes de Io nuestro (honra, familia y silencio), cualquier referencia personal nos pertenece y sólo bajo nuestra autorización será posible tener acceso a cuanto nos une a la tierra..."
\end{abstract}

Almodio. Prior y abad del Monte de San Miguel ${ }^{5}$.

La actual Sociedad de la Información o Sociedad del Conocimiento aborda principalmente un modelo de organización social caracterizado por una sociedad inmersa en una nueva revolución industrial propiciada por el desarrollo de nuevas tecnologías de la información y de las comunicaciones (TIC), que como consecuencia de lo anterior centra su poder en función de la posesión y capacidad de uso de la información disponible. La potencialidad de la informática en la sociedad moderna está referida a un "Conjunto de conocimientos científicos y técnicas que hacen posible el tratamiento automatizado de la información por medio de

5 Tascón, L. R. (2005). El tratamiento por la empresa de datos personales de los trabajadores. (Análisis del Estado de la cuestión). 1 ed., España: Aranzadi S.A. 
ordenadores"6. Evidentemente, los avances informáticos han contribuido de manera decisiva a mejorar nuestra calidad de vida; pero igualmente nunca como ahora nuestra intimidad ha estado más amenazada. $Y$ es que los peligros que comporta el tratamiento automatizado de datos personales rodean todos y cada uno de los ámbitos en que se desarrolla nuestra existencia, específicamente en el ámbito laboral.

Lo anterior explica las frecuentes inquietudes manifestadas por gobiernos y organizaciones supranacionales en atención a regular jurídicamente el manejo informático de los datos personales. Las nuevas tecnologías de la información y de las comunicaciones, como ordenadores, Internet, correo electrónico, teléfonos móviles, grabadoras (de la palabra, de la imagen o del sonido), entre otras, han alcanzado un progresivo avance en su utilización general que ha trascendido también al ámbito de las relaciones laborales. No obstante, uno de los temas que se plantea hoy en día en el campo de las relaciones laborales está en conexión, más que con su utilización como herramienta de información y comunicación, con las repercusiones que el uso de estas nuevas tecnologías puede provocar en el derecho fundamental de la intimidad del trabajador e inviolabilidad de las comunicaciones, establecidos en el Artículo 18.1 y 18.3 de la Constitución española (CE) y vinculados a la dignidad personal de que habla el artículo 10.1 del mismo texto, cuando el empresario procede a controlar el cumplimiento de sus obligaciones y deberes laborales con fundamento

6 Luján A, J. (2003). Protección de datos de carácter personal y contrato de trabajo. Pamplona, España: Aranzadi S.A. en el ejercicio del poder de dirección empresarial, imprescindible para la buena marcha de la organización productiva y que es el reflejo de otros derechos reconocidos constitucionalmente en los artículos 33 y 38 del Texto fundamental (Propiedad privada y libertad de empresa), plasmados en el artículo 20 del Estatuto de los Trabajadores $(\mathrm{ET})^{7}$.

El ordenamiento jurídico colombiano reconoce este derecho en respuesta a las continuas tensiones que se dan entre lo particular o personal y aquello que podría calificarse como de interés público o general, señalando en el art. $15 \mathrm{CP}$, que toda persona por el hecho de serlo goza de protección en lo que atañe a su vida privada ${ }^{8}$. La Corte Constitucional señala que la intimidad no puede referirse únicamente a las categorías de lo público y lo privado y la define como "la existencia y goce de una órbita reservada en cada persona, exenta del poder de intervención del Estado o de las intromisiones arbitrarias de la sociedad, que le permite a dicho individuo el pleno desarrollo de su vida personal espiritual y cultural"9, es decir, el espacio de aislamiento del que goza todo individuo que solamente puede ser penetrado por extraños cuando medie el consentimiento de su titular o una orden judicial. ${ }^{10}$

$7 \quad$ Apilluelo, M. M. (2003). Contornos de control empresarial de la intimidad del trabajador ante las nuevas tecnologías y a la luz de la doctrina judicial. Pamplona, España: Aranzadi S.A.

8 Artículo 15 Constitución Política colombiana. Derecho a la intimidad. - Habeas Data. Inviolabilidad de documentos privados. Protege no solamente la honra y el buen nombre contra la injuria y la calumnia sino también la imagen y el crédito- el prestigio que de ellos se deriva para preservarlos mediante el acceso a la información personalizada y el derecho a la rectificación de informaciones no verídicas y su actualización.

$9 \quad$ Corte Constitucional. Sentencia T-787 de agosto 18-2004.

10 Corte Constitucional. Sentencia T-696-1996. 
El ejercicio del poder de dirección empresarial permite la adopción, por la empresa, de las medidas que estime convenientes para la vigilancia, control y verificación del cumplimiento por parte del trabajador de sus obligaciones laborales, con la condición de mantener en su adopción y aplicación la consideración debida a la dignidad humana y a la intimidad. En atención a ese cumplimiento y como declaración de principio, los medios tecnológicos de producción de la palabra, imagen o sonido, como también los medios informáticos, no suponen por sí mismos medios agresivos que ataquen este derecho fundamental a la intimidad de los trabajadores. ${ }^{11}$ También debe tenerse presente que el concepto de intimidad no es unívoco para todas las ramas del derecho; es perfectamente posible y, de hecho así sucede, que el umbral de protección de la intimidad personal esté menos coactivamente tutelado en el ámbito laboral que en el penal, el cual únicamente protege el bien jurídico en cuestión ante ataques intolerables por parte de otros sujetos. Por ello, precisamente, es perfectamente posible hablar de ámbitos de protección laboral, civil, penal e incluso constitucional del derecho a la intimidad. ${ }^{12}$

\section{EVOLUCIÓN HISTÓRICA ${ }^{13}$}

Al referirnos a los antecedentes de la regulación sobre la protección de datos, merece especial

11 Apilluelo, M. M. Óp. cit., págs. 2/11.

12 Arias, A. y Rubio, F. (2006). El derecho de los trabajadores a la intimidad. Navarra-España: Aranzadi S.A.

13 Rivera S, M. del R. (2009). Seguridad informática y comunicaciones electrónicas. Universidad Carlos III de Madrid. Facultad de Derecho y Ciencias Sociales. Madrid-España. Manuscrito no publicado. reconocimiento el trabajo que en este sentido ha realizado Alejandra Castro Bonilla (2005) en su artículo “La protección del derecho a la intimidad en el tratamiento de datos personales: el caso de España y la nueva legislación latinoamericana", en el que se fundamenta la síntesis histórica a la que se hará referencia a continuación. El control virtual que se ejerce sobre la vida íntima de las personas debe tener una regulación, que se ha iniciado en diversas geografías desde la segunda mitad del siglo XX, basada en un derecho de tercera generación que muchos denominan ya "libertad informática", sin que exista una intersubjetividad entre los juristas con respecto a la naturaleza jurídica autónoma de ese derecho, como un derecho novedoso o como concreción histórica de un derecho antiguo.

El derecho a la intimidad es un derecho relativamente reciente cuyo origen se remonta al conocido artículo The Right to Privacy, de S. Warren y L. Brandeis, quienes exponían la inquietud sobre la necesidad de que el derecho a la intimidad o los acontecimientos de la vida privada de un individuo recibiesen la protección adecuada frente a la injerencia de los medios de comunicación. En ese momento los juristas se refirieron a un derecho de exclusión (The Right to be let alone) como una reafirmación de la intimidad y la individualidad. Con la era de la información, efectivamente esa privacidad se ve debilitada, tal como lo afirma Suñe (2000) ${ }^{14:}$ "Al entrar en la era informática, cosa que sucederá inmediatamente después de la segunda guerra mundial,

14 SUÑE, L. (2000). Tratado de Derecho Informático. Vol. 1., Madrid: Universidad Complutense de Madrid. 
el ser humano se vuelve más y más de cristal, a partir del tratamiento masivo de los más diversos datos, de las múltiples acciones de su vida cotidiana, que son susceptibles de quedar y de hecho quedan registrados en un ordenador."

Así entonces, en el Consejo de Europa, en 1967, se conformó una comisión consultiva de expertos para analizar el impacto de las nuevas tecnologías de la información sobre los derechos de los ciudadanos. Un año después la Asamblea de dicho Consejo emitió la Resolución 509/1968 sobre "los derechos humanos y los nuevos logros científicos y técnicos", que si bien no hace alusión explícita a la protección de datos como tal, sí revela la necesidad de establecer mecanismos de protección tanto sobre la vida privada de las personas como sobre otros derechos fundamentales que podrían afectarse con la aparición de nuevas tecnologías. El mérito inicial correspondió a un Estado integrado en la antigua República Federal Alemana, el Land Hessen, que promulga su Ley el 7 de octubre de $1970 .{ }^{15}$ El primer Estado propiamente soberano que dispuso de lo que abreviadamente se denominan "Leyes de protección de datos" fue Suecia, que promulgó la suya en $1973 .^{16}$

Otro antecedente podría ser la Fair Credit Reporting Act del 26 de octubre de 1970, en la que no se hace mención a archivos automatizados pero sí se intenta una primera regularización del tratamiento genérico de los datos

\footnotetext{
15 Castro, B. (2005). La protección del derecho a la intimidad en el tratamiento de datos personales: el caso de España y la nueva legislación latinoamericana. Disponible en http://www.juridicas.unam.mx/publica/ librev/rev/derhum/cont/57/pr/pr33.pdf

16 Suñe, L. Óp. cit., pág. 37.
}

personales del individuo, como norma de origen de la Privacy Act del 31 de diciembre de 1974; ambas en Estados Unidos de Norteamérica. A partir de entonces, múltiples países de la Comunidad Europea dieron sus iniciativas para la legalización y control del manejo privado y público de los datos personales de sus ciudadanos a través de Internet y otros medios de comunicación, considerando la evidente desventaja de poder que tiene el usuario en relación con el proveedor de servicios. Los países americanos y demás naciones en vías de desarrollo se han quedado rezagados en esa carrera del Derecho Comparado y aún del Derecho Internacional, pues con algunas salvedades existe una desregularización total en la protección de los datos personales para el resguardo del derecho a la intimidad. Colombia expide la Ley Estatutaria de Habeas Data en el año 2008. ${ }^{17}$

La gran influencia de EE.UU., quien incluso, a principios de los noventa intenta detener la aprobación de una ley al respecto en Argentina, se ha hecho sentir en la región por la amenaza anunciada de un menoscabo en las inversiones. La gran nación del Norte considera que regular el avance de las autopistas de la información deviene en un menoscabo al desarrollo industrial y económico, lo que coincide con su legislación y política economicista. ${ }^{18}$ Europa ha entendido la

17 Ley Estatutaria 1266 de 2008 (31 de diciembre), Congreso de la República, por la cual se dictan las disposiciones generales del Habeas Data y se regula el manejo de la información contenida en bases de datos personales en especial la financiera, crediticia, comercial, de servicios y la proveniente de terceros países. Declarada exequible por la Corte Constitucional mediante Sentencia C-1011 del 16 de octubre de 2008.

18 Recordemos, por ejemplo, la diferenciación entre la concepción comercialista del Copyright y la humanística (centrada en los derechos humanos del autor) del Droit d'auteur de la doctrina francesa que han asumido la Unión Europea y los países de tradición latina. 
necesidad de prevalecer el derecho a la intimidad sobre la libertad de comercio y constitucionalmente ya se ha consagrado tal protección en diversas naciones. Tal es el caso de la pionera Constitución portuguesa de $1976^{19}$, la austriaca de 1978 y, especialmente, la Constitución española de 1978 que vislumbrando muy tempranamente los problemas derivados del uso masivo de las nuevas tecnologías informáticas, con base en las experiencias foráneas más que en las propias, precisó en el apartado 4 de su artículo 18, claramente influenciado por el artículo 35 de la Constitución portuguesa, que "La ley limitará el uso de la informática para garantizar el honor y la intimidad personal y familiar de los ciudadanos y el pleno ejercicio de sus derechos".

Diversos Estados soberanos, con anterioridad al Convenio 108 firmado por el Consejo de Europa en 1981, emitieron sus leyes para la protección de datos personales. Tal es el caso de la ley sueca de 11 de mayo de 1973 sobre archivos automatizados ${ }^{20}$, la ley alemana de 27 de enero de $1977^{21}$, la ley francesa de 6 de enero de 1978, la ley noruega de 9 de junio de 1978, la ley austriaca de 18 de octubre de 1978, y la ley de Luxemburgo de 31 de marzo de 1979. En el Consejo de Europa, la iniciativa para fijar una legislación universal en la materia tuvo su comienzo incluso antes de la ley de datos de

$19 \quad$ El Art. 35 regula la protección de los datos personales en los registros informáticos con miras a resguardar la intimidad de los ciudadanos.

20 Esta ley es conocida como Data Lag y protege a los individuos del uso de la informática en la manipulación de sus datos.

21 Recordemos el antecedente de la "Datenshutz" del 7 de abril de 1970, del Estado alemán de Hesse, que es el origen de la Datenshutz Federal.
Hesse en 1970. Es así como en 1964 se instauró el Comité de Cooperación Jurídica del Comité de Ministros, que dos años después incluye la inquietud sobre protección a la intimidad frente a las nuevas tecnologías en la Recomendación 509 conocida por la Asamblea. A partir de esas observaciones, se acuerda nombrar un Comité de expertos en el seno del Comité Europeo de Protección Jurídica, que luego de varias discusiones decide iniciar con el Proyecto de Convenio Internacional ante la evidente promulgación aislada de leyes que intentaban la protección de la intimidad.

En 1973, se aprueba en el Consejo de Ministros la Recomendación $N^{\circ} 22$ sobre protección de la intimidad de los datos en el sector privado, y en 1974 la Recomendación No29, referida al sector público. Estas recomendaciones constituyen los antecedentes para que en 1976 el Consejo de Europa encomendara al Comité de expertos (a través del Consejo de Ministros), la elaboración de un Proyecto de Convenio de la región para la protección de datos que fue abierto a la firma de los Estados en Estrasburgo el 28 de enero de 1981.

Hacia el año 1981 el Consejo de Europa abordó los problemas que podían plantear las incipientes nuevas tecnologías de la información y de la comunicación (TIC) y adoptó el Convenio 108 para la protección de las personas con respecto al tratamiento automatizado de datos de carácter personal. España ratificó el Convenio en 1984 y fue publicado en el Boletín Oficial del Estado (BOE), del 15 de noviembre de 1985. Es importante destacar que durante el proceso de aprobación y ratificación, el Tribunal Constitucional 
alemán emitió su famosa Sentencia del 15 de diciembre de 1983 sobre la Ley del Censo. En dicha resolución el Tribunal alemán utiliza el término del derecho a la autodeterminación informativa haciendo alusión a la protección del derecho a la intimidad frente a las nuevas tecnologías de la información, lo que se ha conocido en doctrina como libertad informática o derecho informático, que le permite al individuo tener potestades e injerencia en el manejo que entidades públicas y privadas hagan sobre sus datos personales. Este precedente jurisprudencial señala que el interesado posee la autodeterminación informativa como una facultad para el resguardo del derecho a la intimidad, haciendo especial hincapié en la necesidad de evitar la elaboración de un perfil de la persona a partir de la interacción de archivos que resguardan distintos datos personales del individuo. ${ }^{22}$

Posteriormente y en cumplimiento de este mandato, la Ley Orgánica 5/1992 de 29 de octubre, de Regulación del Tratamiento Automatizado de Ios Datos de Carácter Personal (LORTAD), aspiraba a "hacer frente a los riesgos que para los derechos de la personalidad puede suponer el acopio y tratamiento de datos por medios informáticos" por lo que implantó diferentes mecanismos cautelares dirigidos a prevenir "las violaciones de la privacidad que pudieran resultar del tratamiento de la información". Siete años más tarde, la LORTAD fue sustituida por la Ley Orgánica 15/1999 de 13 de diciembre, de Protección de Datos de Carácter Personal

22 Castro B, A. (2005). La protección del derecho a la intimidad en el tratamiento de datos personales: el caso de España y la nueva legislación latinoamericana. Disponible en http://www.juridicas.unam.mx/ publica/librev/rev/derhum/cont/57/pr/pr33.pdf.
(LOPD), que en esencia comparte la misma filosofía y objetivos de su predecesora, así como buena parte de su articulado. No obstante, también es cierto que, como refleja su propio título, la nueva ley parece abarcar un mayor ámbito de protección material que buscaría "Garantizar y proteger, en lo que concierne al tratamiento de los datos personales (en general), no únicamente a su tratamiento automatizado (art.1 LORTAD), las libertades públicas y los derechos fundamentales de las personas" (art. 1 LOPD). Esto es, la protección que la ley regula se extiende tanto a "Los datos de carácter personal registrados en soporte físico que los haga susceptibles de tratamiento", como "a toda modalidad de uso posterior de estos datos por los sectores público y privado" (art. 2 LOPD) ${ }^{23}$.

Pero ha sido en el ámbito comunitario donde más lejos se ha llevado esta necesidad de regulación, principalmente al aprobarse la Directiva 95/46/CE del 24 de octubre de 1995, del Parlamento Europeo y del Consejo, relativa a la protección de las personas físicas en lo que respecta al tratamiento de datos personales y a la libre circulación de estos datos, complementada en el sector de las comunicaciones electrónicas por la Directiva 2002/58/CE del Parlamento Europeo y del Consejo de 12 de junio de 2002. La necesidad de regular el tratamiento automatizado de datos de carácter personal fue acogida incluso en la Carta de los Derechos Fundamentales de la Unión Europea cuyo artículo 8, rubricado "Protección de datos de carácter personal”, dispuso que "toda persona tiene derecho a la Protección de los Datos

23 Luján, A. J. Óp. cit. 
de carácter personal que la conciernan. Estos datos se tratarán de modo leal, para fines determinados y sobre la base del consentimiento de la persona afectada o en virtud de otro fundamento legítimo previsto por la ley. Toda persona tiene derecho a acceder a los datos recogidos que la conciernan y a su rectificación. El respeto de estas normas quedará sujeto al control de una autoridad independiente". Como es sabido, la Carta va a ser incorporada como Parte II de la futura Constitución para Europa cuyo proyecto, elaborado por la Convención de conformidad con la Declaración de Laeken (diciembre de 2001) ha sido aprobada por los quince Estados miembros de la Unión Europea durante la Cumbre de Salónica (19-20 de junio de 2003).

\section{EL CONTRATO DE TRABAJO Y LOS DERECHOS FUNDAMENTALES}

Los derechos fundamentales y el contrato de trabajo ${ }^{24}$, conjuntamente con las normas legales

24 Los derechos fundamentales. El concepto de derecho fundamental, es quizá el más importante de las Constituciones contemporáneas. Colombia acogió esta figura en la Constitución de 1991. Son los derechos inherentes a la persona humana. Usualmente se les ha identificado con los derechos individuales, sin embargo en Colombia han sido reconocidos por la Corte Constitucional algunos derechos pertenecientes a la llamada segunda generación, es decir, ha reconocido como derechos fundamentales ciertos derechos sociales que son necesarios para que la persona humana cuente con una vida digna. La Corte Constitucional ha sostenido que el Constituyente no determinó en forma taxativa cuáles eran los derechos constitucionales fundamentales. Para la Corte hay criterios principales y subsidiarios de interpretación. Acoge como principales: el que se trate de un derecho esencial de la persona y el reconocimiento expreso de la Constituyente (un caso ejemplificativo es el artículo 44 que se refiere a los derechos de los niños como derechos fundamentales); acoge como criterios auxiliares, los cuales no bastan por sí solos: la inclusión del derecho en tratados internacionales, que se trate de un derecho de aplicación inmediata; que posea un "plus" para su modificación (se refiere a los que requieren de referendo para ser reformados); y por último la ubicación y denominación. Para que un determinado derecho sea tenido como fundamental la Corte Constitucional colombiana considera que y convencionales que los desarrollan y concretan, constituyen un primer límite general a las facultades organizativas y controladoras del empresario; es por ello que, el ejercicio de dichas facultades, tiene un carácter restrictivo si consideramos la posición prevalente de los derechos fundamentales en el ordenamiento laboral español (SSTC 90/1997, 6 de mayo; 29/2002, 11 de febrero). El Tribunal Constitucional español (TC) abre una nueva perspectiva que puede catalogarse de menos contractualista para apreciar la efectividad de los derechos fundamentales en el desarrollo de la relación laboral reafirmando, indirectamente, la superioridad de los derechos fundamentales de los trabajadores en relación con los de la empresa, ${ }^{25}$ porque nada legitima que el trabajador soporte limitaciones injustificadas y omnímodas de sus derechos fundamentales en razón a que "la desigual distribución del poder social entre trabajador y

debe reunir tres requisitos: conexión directa con los principios constitucionales, eficacia directa y contenido esencial (núcleo básico del derecho). Corte Constitucional. Sentencia T- 778 de junio de 1992. Magistrado Ponente: Ciro Angarita Barón.

Los derechos fundamentales son facultades que disfrutan los sujetos de derecho de todo sistema constitucional moderno, respetuoso de los principios del Estado de derecho; tienen como denominador común la fundamentación de los elementos básicos e integradores de la dignidad humana, base sobre la que se apoya el espíritu y el ejercicio de estos derechos.

EI Contrato de Trabajo. Su concepción jurídico-positiva está referida a aquel contrato que vincula el trabajador que presta voluntariamente sus servicios retribuidos por cuenta ajena y dentro del ámbito de organización y dirección de otra persona física o jurídica denominada empleador o empresario. Art. 1, Real Decreto Legislativo 1/1995, de 24 de marzo, por el que se aprueba el texto refundido de la Ley del Estatuto de los Trabajadores (ET).

En Colombia, el Código Sustantivo del Trabajo en sus artículos 22 y 23 establece que el Contrato de Trabajo es aquel por el cual una persona física, denominada el trabajador, se obliga a prestar servicios personales para una persona física o jurídica denominada el empleador, bajo la dependencia y subordinación de éste, quien a su vez, se obliga a pagar por estos servicios una remuneración determinada.

25 Prados, J. (2001). Contrato y relación de Trabajo. Madrid: Tecnos, en Arias, D. A. y Rubio, S. F. (2006). El derecho de los trabajadores a la intimidad. Navarra: Aranzadi S.A., pág. 17. 
empresario y la distinta posición que éstos ocupan en las relaciones laborales elevan en cierto modo el riesgo de eventuales menoscabos de los derechos fundamentales del trabajador" (STC 129/1989, 17 de julio). Doctrinariamente, es claro, que la existencia del contrato de trabajo no implica privación de los derechos fundamentales a quienes prestan servicio en las organizaciones productivas; el problema surge porque los derechos fundamentales no son absolutos, pudiendo ceder ante otros bienes o intereses constitucionalmente relevantes, por lo tanto, el contrato de trabajo exige adaptar tales derechos a las legítimas exigencias de la empresa.

\subsection{El derecho a la intimidad, la privacidad y la autodeterminación informativa en España}

El derecho a la intimidad es inherente a la personalidad y, por lo tanto, formador de la dignidad humana. Esto implica que el individuo sea respetado como tal y que tenga la posibilidad de desarrollar su esencia única y genuina como ser humano irrepetible; por ello, la sociedad ha de respetar el ámbito individual único e inviolable en el que desarrolla su ser y ejerce otros derechos individuales que le son inherentes como ser humano único. Al referirnos a este derecho, cabe destacar la investigación realizada por Rivera (2009) ${ }^{26}$, en la que se ilustran aspectos relacionados con su origen, características y regulación en España. Al respecto se tiene que:

\footnotetext{
26 Rivera S, M. de R. (2009). Seguridad Jurídica y Comunicaciones Electrónicas. Universidad Carlos III de Madrid, Departamento de Derecho Privado, Madrid-España. Manuscrito no publicado.
}

A partir de los años sesenta se han elaborado documentos internacionales que incorporan principios tendientes a proteger los datos personales y algunos derechos fundamentales (intimidad, buen nombre, honra, honor, debido proceso y libertad, entre otros) de cara al contexto de la sociedad de la información.

En la Constitución española se establecen límites a "la informática" para proteger derechos como el de la intimidad y el honor de las personas. El legislador, con base en esto, regula la acción de protección de datos de la persona, y el Tribunal Constitucional en sus providencias y la doctrina en sus tratados asimila en su constitución, desarrollo y efectos jurídicos sustantivos y materiales al recurso de Habeas Data latinoamericano. El derecho a la intimidad ha evolucionado en la legislación española desde un derecho de exclusión en el que se acentuaba el derecho a la privacidad o "derecho a estar solo", a una dimensión de derecho facultativo, es decir, que le permite ejercer acciones en defensa de su vida privada.

España ha considerado esta nueva dimensión del derecho a la intimidad, designándolo como DERECHO A LA AUTODETERMINACIÓN INFORMATIVA, en razón a los cambios surgidos en torno a la nueva noción del derecho a la intimidad y ante el uso de nuevas tecnologías de la información y la comunicación que lo afectan. El doctor Pablo Lucas Murillo de la Cueva, citado por Castro Bonilla, A. (1990) ${ }^{27}$ en su obra El

27 Castro B, A. (2005). La protección del derecho a la intimidad en el tratamiento de datos personales: el caso de España y la nueva legislación latinoamericana. Pág. 5. Disponible en: http://www.juridicas. unam.mx/publica/librev/rev/derhum/cont/57/pr/pr33.pdf. 
derecho a la autodeterminación informativa, afirma que en atención a la protección que exige este nuevo bien jurídico todo Estado democrático debe prever: 1 . El reconocimiento a cada individuo del derecho a acceder a la información personal que le afecte, especialmente a la existente en los bancos de datos informatizados. 2. El reconocimiento a cada individuo del derecho a controlar de una forma razonable, la transmisión de la información personal que le afecte. 3. Para garantizar el derecho a la intimidad individual, las leyes deben regular: la limitación del periodo de tiempo durante el que se pueden conservar los datos personales; la definición de los objetivos para los que puede usarse dicha información, que además han de declararse al momento de iniciar la recolección de datos; garantías para hacer efectiva la calidad de los datos personales, es decir, su veracidad, integridad y actualidad y la prohibición de la revelación de datos personales.

La Sentencia 134/1999 del 15 de junio del Tribunal Constitucional de España, establece que: "El derecho a la intimidad garantiza al individuo un poder jurídico sobre la información relativa a una persona o a su familia pudiendo imponer a terceros, sean éstos simples particulares o poderes públicos su voluntad de no dar a conocer dicha información o prohibiendo su difusión no consentida."

Se busca establecer la diferencia entre intimidad y libertad informativa, y para el efecto en España se remite a la Sentencia 292/2000 de 30 de noviembre, donde se asignan funciones diferentes tanto al derecho a la intimidad como al derecho fundamental a la protección de datos. La función del derecho fundamental a la intimidad, del artículo 18.1 CE, es la de proteger frente a cualquier invasión que pueda realizarse en aquel ámbito de la vida personal y familiar que la persona desea excluir del conocimiento ajeno y de las intromisiones de terceros en contra de su voluntad. (...) En cambio, el derecho fundamental a la protección de datos persigue garantizar a esa persona un poder de control sobre sus datos personales, sobre su uso y destino, con el propósito de impedir su tráfico ilícito y lesivo para la dignidad y derecho del afectado. Al respecto, Rodríguez de las Heras Ballell ${ }^{28}$ precisa que privacidad no es anonimato y debe interpretarse como el derecho a controlar los datos personales y cualquier otra información relacionada con preferencias, comportamientos e intereses. El problema no es de límites, es de control de la información. La privacidad no significa un derecho al total anonimato; la privacidad y el anonimato son conciliables frente a objetivos de política pública asociados, por ejemplo, a fraude financiero o infracciones a los derechos de autor.

Tratadistas del derecho como Alejandra Castro Bonilla, citada anteriormente, consideran el derecho a la intimidad como un componente de derecho facultativo, en virtud del cual, el individuo está en pleno ejercicio de defensa de su intimidad pudiendo exigir acciones a entes públicos y privados para el control de la vida privada, facultad que han denominado (poder de oposición y

28 Rodríguez de las Heras, B. T. (2008). Legal Framework for Personalization-Based Business Models. In: Personalization of Interactive Multimedia Services: a Research and Development Perspective -CB. Pazos-Arias, José J. y Martín López Nores (editors). Madrid: Nova Science Publishers Inc., pp. 3-23. 
control sobre los datos personales). A esta nueva tendencia de concebir el derecho a la intimidad como un derecho activo se le conoce como HABEAS DATA, aunque la correcta acepción según Castro Bonilla sería AUTODETERMINACIÓN INFORMATIVA, en razón a que, precisamente, el Habeas Data es el recurso procesal de que dispone el individuo para defender el derecho a la intimidad en cuanto al control y disposición de sus datos personales.

Desde la perspectiva laboral, el derecho fundamental a la intimidad ha sido reconocido al más alto nivel jurídico en el art. 18 CE y en el art. 18 de la Declaración Universal de los Derechos Humanos (1948), cuando dispone que "Nadie será objeto de injerencias arbitrarias en su vida privada, su familia, su domicilio o su correspondencia". Pero la norma que más claramente delimita la intimidad en la relación laboral es el propio Estatuto de los Trabajadores (ET). Su contenido se concreta en la facultad de excluir del conocimiento ajeno, cualquier hecho comprendido dentro del propio ámbito que reserve el ciudadano para sí mismo y para su familia. Ahora bien, la relación laboral exige ejercitar una actividad humana en ámbitos alejados de la estricta vida personal o familiar, porque el ejercicio del derecho al trabajo se ejerce fuera de este ámbito personal aunque constituya una proyección de estos aspectos.

El poder de dirección del empresario (art. 20 ET), considerado instrumento jurídico imprescindible para la correcta marcha de la organización productiva, atribuye a este, entre otras facultades, la de adoptar las medidas que estime más oportunas de vigilancia y control para verificar el cumplimiento, por parte del trabajador, de sus obligaciones laborales. Pero esa facultad ha de ejercerse en todo caso, como es lógico, dentro del debido respeto a la dignidad del trabajador como expresamente lo regula el ET en sus artículos 4.2.e) y 20.3. El trabajador activo está obligado a cumplir con sus deberes laborales, los que se materializan con respecto al empresario en el poder de dirección y control que consagra el art. 20 del ET.

Algunos tratadistas consideran que el problema no es cómo se realiza el control (métodos utilizados) sino hasta dónde puede llegar la vigilancia; así por ejemplo, tratándose del derecho del empresario a la apertura de los mensajes de la cuenta de correo electrónico del trabajador, se debe tener presente que en el ámbito laboral no cabe realizar actividades de carácter personal y que los medios de trabajo son propiedad de la empresa. Así lo ha interpretado la Sentencia del Tribunal Superior de Justicia español (STSJ-5.2.2000) cuando estima que la correspondencia transmitida desde la empresa por correo electrónico no tiene carácter privado, al ser emitida con instrumentos propiedad de la empresa, por lo que no cabe la invocación del derecho a la intimidad del trabajador; sin embargo, este derecho del empresario no es absoluto y el control debe ejercerse teniendo en consideración el respeto a la dignidad, el derecho al honor, a la intimidad personal y familiar, y a la propia imagen. El derecho al secreto en las comunicaciones electrónicas solo justifica y admite la intromisión en estos ámbitos, al igual que las requisas sobre la persona del 
trabajador, sus efectos personales o casilleros, etc., cuando tienen como finalidad la protección del patrimonio de la empresa y/o del resto de los trabajadores; cuando se efectúa en el lugar de trabajo y en horas laborables; entre otras situaciones. En todo caso, las medidas de control adoptadas por la empresa para vigilar la utilización del correo electrónico, como cualquier otro tipo de actividad, deberán ser comunicadas previamente al trabajador; de ser necesaria la disposición de medidas de control se debe emitir un informe previo a la instalación o a la modificación de las mismas; igualmente, estas medidas deberán ser justificadas, idóneas para la finalidad pretendida, necesarias en la medida que constituyan prueba de conducta irregular con fines de despido y, finalmente, equilibradas o proporcionadas. ${ }^{29}$

En conclusión, la jurisprudencia constitucional ha mantenido como lineamiento legal que, el ejercicio de las facultades organizativas y disciplinarias del empleador no puede, en ningún caso, utilizarse para la producción de resultados inconstitucionales lesivos de los derechos fundamentales del trabajador (STC 94/1984, 16 de octubre), ni tampoco para sancionar laboralmente el ejercicio legítimo de tales derechos por parte del trabajador (STC 11/1981, 8 de abril). Así entonces, las medias restrictivas del derecho

29 Respecto al principio de proporcionalidad, la Sentencia del Tribunal Constitucional español (STC 98/2000 de 10 de abril) establece que las medidas de control impuestas tendrán que "[...] ser las indispensables y estrictamente necesarias para satisfacer un interés empresarial merecedor de tutela y protección, de manera que si existen otras posibilidades menos agresivas y afectantes del derecho en cuestión, habrá que emplear estas últimas". Ej., instalación de un circuito cerrado de televisión en una zona concreta y solo durante el periodo de tiempo necesario para comprobar las irregularidades cometidas por el trabajador. En El despido por utilización personal del correo electrónico, pág. 1-29. Disponible en http://www.bob.bosch.es/data/laboral/ comentarios/289.html. fundamental a la intimidad en la relación laboral se imputan generalmente al empresario. ${ }^{30}$

\subsection{El derecho a la propia imagen}

Este derecho asegura el interés del sujeto en evitar la difusión incondicionada de su aspecto físico, que constituye el primer elemento configurador de su intimidad y de su esfera personal, en cuanto instrumento básico de identificación y proyección exterior, factor imprescindible para su reconocimiento como individuo. Este derecho tiene su limitación en la relación de trabajo a través de dos vías: primera, que en el cumplimento del objeto del contrato de trabajo se exija la limitación del derecho fundamental de la propia imagen como ocurriría con los presentadores de televisión o los y las modelos. En este caso la limitación se entiende justificada por el tipo de labor que el trabajador voluntariamente acepta desarrollar; segundo, si la limitación no ha sido directamente pactada, entonces se requiere por parte del empresario justificar esa necesidad. Esto implica que el empleador debe acreditar que no es posible otra forma de alcanzar los objetivos organizacionales o el interés empresarial.

Los aspectos en que puede plasmarse la imagen del trabajador son muy variados y muchos de ellos tienen relación con la apariencia física o externa: vestimenta, aseo, cuidado del cabeIlo, uso de adornos o complementos, etc.; el trabajador tiene plena autonomía y capacidad de decisión sobre todos y cada uno de ellos en el

30 Arias, A. y Rubio, F. (2006). El derecho de los trabajadores a la intimidad. (Ed. Primera). Navarra-España: Aranzadi S.A., pág. 48. 
evento o en situaciones aisladas del trabajo. En el lugar o tiempo de trabajo son aspectos que hay que conjugar con los criterios organizativos de la empresa o con sus exigencias productivas. Algunos ejemplos de la casuística judicial son:

- El empresario está legitimado para exigir al trabajador que preste servicio completamente afeitado, si tiene contacto directo con los clientes (STC 170/1987, 30 de octubre). Caso de un barman que había decidido dejarse barba.

- No se justifica la orden empresarial de prohibir a un cocinero que lleve barba y perilla si estas se encuentran debidamente recortadas y aseadas, porque la orden resulta desproporcionada. (STSJ de Madrid 18-4-2001).

- En caso de que el Convenio Colectivo obligue a vestir uniforme, constituye causa de despido acudir al puesto de trabajo con una camiseta distinta, con un mensaje reivindicativo de un conflicto laboral. (STSJ de Andalucía/ Granada de 13-11-2001).

\subsection{Derecho a la no discriminación}

La protección de datos de carácter personal es un elemento esencial en el ejercicio de este derecho, por cuanto garantiza que esta discriminación no se produzca; la protección de estos datos es, en consecuencia, un elemento constitutivo del principio de no discriminación. La Ley Orgánica de Protección de Datos contempla supuestos de datos especialmente protegidos, entre ellos los que hagan referencia al origen racial, a la salud o a la vida sexual, que sólo podrán ser recabados, tratados y cedidos cuando por razones de interés general así lo disponga una ley o el afectado lo consienta expresamente.

La ley distingue dentro de los datos de carácter personal, los datos especialmente protegidos o sensibles a los que les otorga un régimen especial de protección en su recolección y tratamiento. A estos efectos el artículo 7.1 de la LOPD 15/1999, distingue tres categorías o tipos $^{31}$ : 1. Datos relativos a ideología, religión, creencias y afiliación sindical: la ley establece la prohibición de crear ficheros con la finalidad exclusiva de almacenar datos de carácter personal que revelen afiliación sindical, religión, origen racial o étnico, vida sexual o ideología (art. 7.4 LO 15/1999). 2. Datos relativos al origen racial, salud y vida sexual: en este caso, para este tipo de información se hace necesario el consentimiento del interesado, excepto cuando por razones de interés general una ley disponga el tratamiento de esta información (por ejemplo, reconocimientos médicos en materia de prevención de riesgos laborales) y cuando se considera que el tratamiento de datos relativos al origen racial, salud o vida sexual resulta necesario para la prevención o para el diagnóstico médico, la prestación de asistencia sanitaria o servicio médico; siempre y cuando el tratamiento de dichos datos se realice por parte de un profesional sanitario sujeto a secreto profesional (art. 7.6 LO 15/1999). 3. Datos relativos a las infracciones penales y administrativas: la ley prohíbe que sean incluidos en otros ficheros distintos de los de la Administración Pública competentes

31 La protección de datos de carácter personal en la relación de trabajo. Disponible en: www.westlaw.es. 
(los supuestos previstos en la norma reguladora. Art. 7.5 LO 15/1999). Establece la ley que, a pesar de que se trate de infracciones que puedan tener relevancia en la relación de trabajo, no podrán ser recogidas ni tratadas por el empresario, por ejemplo, infracciones en materia de tráfico cometidas por quienes trabajan como transportistas, mensajeros, comerciales, etc.

Debe tenerse en cuenta que la exigencia del consentimiento en el acopio y tratamiento de datos sensibles no sustituye ni neutraliza los derechos fundamentales a la intimidad, libertad religiosa, ideológica y sindical en la relación de trabajo. Efectivamente, el requerimiento empresarial de cualquier información que se solicite al trabajador, relativa a estos aspectos, se halla sujeta al principio de proporcionalidad. Ello significa que debe justificarse un interés relevante en el conocimiento de la información. A partir de ahí el tratamiento de dicha información quedará supeditado a las obligaciones contenidas en la ley para el tratamiento de informaciones especialmente sensibles.

\subsection{Derecho a la libertad de expresión e información}

Se trata de dos derechos con distinto contenido, límites y efectos regulados por el art. 20.1 $\mathrm{CE}$, literales a y d. La libertad de expresión tiene por objeto pensamientos, ideas y opiniones como también las creencias y los juicios de valor. El derecho a comunicar y recibir libremente información versa sobre hechos que pueden considerarse noticiables, esto es, que impliquen trascendencia pública. Resulta difícil diferenciar la información de la crítica o los aspectos relativos a la opinión sobre el empleador. Un caso particular en el ejercicio de estos derechos es el de los periodistas o profesionales de la información, que contribuyen al efectivo disfrute de las libertades de expresión e información por parte de la sociedad y que, al mismo tiempo, son titulares privilegiados de las mismas, beneficiados además por la especial protección que para el ejercicio de su labor les confiere la cláusula de conciencia y el derecho al secreto profesional (art. $20.1 \mathrm{~d}$ CE). Esta ley habilita al profesional a negarse a participar en informaciones contrarias a sus criterios ideológicos y a solicitar la extinción del contrato de trabajo al amparo del art. 50 ET, en caso de cambio en la línea del correspondiente medio de comunicación.

Aplicaciones esenciales suelen tener las libertades de expresión e información en la Administración Pública por parte de sus funcionarios; en este caso pueden concurrir mayores limitaciones derivadas de la especial sujeción del funcionario público, pero también, mayores márgenes para la expresión e información ya sea por el interés público concurrente. El ejercicio de las libertades de expresión e información en los cargos sindicales o de representación suele verse reforzado por la libertad sindical y las competencias de información y consulta de los representantes.

Este derecho fundamental tiene importantes implicaciones en la relación jurídica laboral, pues cualquier trabajador ve limitada su libertad de expresión de una forma más intensa, ya que no puede poner en peligro la estabilidad ni 
la seguridad de la empresa, debiéndose ponderar en cada caso la relevancia de las opiniones del empleado, la publicidad de las mismas, el ámbito en el que se efectúan o las consecuencias que generan.

La celebración del contrato de trabajo no implica privar al trabajador de los derechos fundamentales que la Constitución le reconoce como ciudadano, entre otros, la libertad de expresión; pero ello no impide reconocer que este derecho no es incondicional sino que se halla sujeto a límites en la relación de trabajo, incluido el ámbito de las administraciones y organismos públicos como lo establece el art. $14 \mathrm{k}$ de la ley 7 de 2007, 12 de abril, Estatuto Básico del Empleado Público y en otras ocasiones en situaciones relacionadas con los derechos al honor, a la intimidad, a la propia imagen, y asimismo el derecho a la protección de la juventud y de la infancia (art. 20.4 CE).

Es importante destacar que las ofensas verbales constituyen límite a la libertad de expresión y por lo tanto son susceptibles de ser sancionadas disciplinariamente. Para el efecto debe tenerse en consideración no sólo el contenido de las expresiones empleadas sino también el contexto en que se ejerce la libertad de expresión. El ejercicio de este derecho puede darse cuando se critica la conducta del otro; en estos eventos el derecho ampara las críticas y reivindicaciones por parte de los representantes sindicales en el ámbito de la empresa así como la denuncia de posibles incumplimientos. Sin embargo, cuando el ejercicio de expresión se realiza en el marco de un conflicto colectivo, términos que en otras circunstancias podrían ser considerados ofensivos no tienen tal consideración en razón del marco en el que se producen (por ejemplo: ladrones, explotadores, esclavistas y otros). Se trata de expresiones tendientes a descalificar determinadas políticas empresariales que, en muchas ocasiones, forman parte de la terminología del conflicto laboral (STC 106/1996, 12 de junio).

Así mismo, el ejercicio de la libertad de expresión se halla sujeto a la buena fe contractual. Al respecto, son diversas las circunstancias que permiten establecer la relación entre la buena fe y la libertad de expresión, por ejemplo, la naturaleza del sujeto empresarial: empleador público o privado; el sujeto que transmite la opinión: trabajador o representante de los trabajadores; y el grado de publicidad de la opinión transmitida: en el seno de la empresa o la apelación a terceros (clientes, opinión pública).

Los límites a la libertad de información del trabajador se encuentran circunscritos a la veracidad de la misma, lo que se traduce en que una información veraz no priva de protección a las informaciones que puedan resultar erróneas. El art. 20.1.d) CE, lo que establece es un deber de diligencia sobre el informador, a quien se le exige que lo que transmita haya sido objeto de contraste con datos objetivos.

No obstante lo anterior, existe una notable diferencia entre las exigencias de veracidad que se demandan a los profesionales de los medios de comunicación, con el deber de diligencia que se le pide al trabajador (STC 4/1996, 16 de enero). Es importante destacar que la libertad de 
información no ampara la difusión de datos o asuntos que quebrantan el secreto profesional.

\subsection{Derecho a la libertad ideológica}

Este derecho protege al trabajador frente a posibles indagaciones o preguntas del empresario, o frente a posibles represalias por sus convicciones, ideas o tomas de posición política o sindical. La decisión de afiliación sindical es, particularmente, una opción ideológica protegida por la ley, y un dato personal cuya revelación es derecho exclusivo del trabajador, que no puede utilizarse para fines distintos de los que motivaron su obtención (STC 142/1993, 22 de abril; STC 94/1998, 4 de mayo; STS 30-3-2001 y STC 11/1998).

La religión o creencia del trabajador es un aspecto de la personalidad que está protegido específicamente en el art. $16 \mathrm{CE}$ y el empresario no puede indagar sobre ello, ni puede sancionarlo por abrazar una u otra confesión religiosa, ni por declararse ateo o agnóstico. El art. $16 \mathrm{CE}$ reconoce el derecho a la libertad ideológica, religiosa y de culto, así como el derecho de la persona a no declarar sobre su ideología, religión y creencias (reiterado en el art. 7 LO 15/1999).

\subsection{Derecho a la tutela judicial efectiva y garantía de indemnidad}

La vulneración del derecho a la tutela judicial efectiva no sólo se produce por irregularidades en los procesos judiciales que ocasionen privación de garantías procesales, sino también a través de la garantía de indemnidad, que significa que, del ejercicio de la acción judicial o de los actos preparatorios o previos a su ejercicio no pueden seguirse consecuencias perjudiciales para el trabajador en su relación de trabajo.

En el ámbito de las relaciones laborales, la garantía de indemnidad se traduce en la imposibilidad de que el empresario adopte "medidas de represalias derivadas de las actuaciones del trabajador encaminadas a obtener la tutela de sus derechos". Represalia que puede manifestarse a través de diversas conductas como el despido u otras medidas sancionatorias, movilidades geográficas o funcionales, perjuicios económicos, etc. (STC 7/1993, 14/1993, 18 de enero).

De no disponer de este derecho fundamental a la tutela judicial efectiva, consagrada por el art. 24.1 de la CE, se privaría en lo esencial de su eficacia ya que el trabajador, por temor a sufrir represalias podría abstenerse de ejercer su derecho a la protección jurisdiccional. Desde la perspectiva del principio de igualdad de trato entre mujeres y hombres, la indemnidad frente a represalias por exigir el cumplimiento de este principio está garantizada expresamente en el art. 9 de la Ley Orgánica 3/2007, 22 de marzo, en los siguientes términos: "Se considerará discriminación por razón de sexo cualquier trato adverso o efecto negativo que se produzca en una persona como consecuencia de la presentación de una queja, reclamación, denuncia, demanda o recurso de cualquier tipo, destinados a impedir su discriminación y a exigir el cumplimento efectivo del principio de igualdad de trato entre hombres y mujeres". 
La garantía de indemnidad cubre todo acto procesal o preprocesal necesario para acceder a los tribunales de justicia, incluyendo la actividad previa no imperativa pero conveniente y aconsejable, cuando del contexto se deduce sin dificultad que aquella está directamente encaminada al ejercicio del derecho fundamental de la tutela judicial efectiva. Al respecto, se ha considerado que vulneran la garantía de indemnidad las represalias adoptadas como consecuencia de: reclamaciones extrajudiciales previas contra el empresario (STSJ Madrid 21-6-2005) y denuncias ante la Inspección de Trabajo; otros actos dirigidos a evitar procesos judiciales, como puede ser una carta remitida por el abogado del trabajador al empresario para conciliar el conflicto y evitar el proceso (STC 55/2004, 19 de abril), escritos dirigidos al empresario para buscar solución a problemas relativos a la seguridad y salud de los trabajadores, reclamaciones al empresario con el propósito de obtener un resarcimiento por un trato vejatorio (STSJ Madrid, 18 de octubre de 2005), o mantener un enfrentamiento manifiesto y claro con pretensiones de beligerancia, en desacuerdo con las condiciones de prestación del servicio y que motivan el despido.

En contra, se ha considerado que no vulnera la garantía de indemnidad la extinción del contrato del trabajador, pese a darse una pluralidad de reclamaciones previas en defensa de sus derechos, cuando existe una desconexión temporal importante entre el ejercicio de las acciones judiciales y el acto extintivo (STSJ Madrid, abril 12 de 2007).

\subsection{Derecho a la protección de datos de carácter personal}

Es importante aclarar que este derecho no busca proteger la privacidad del afectado sino ejercer un control jurídico pleno sobre el uso y destino de la información relativa a la persona. Se entiende por dato: “toda información numérica, alfabética, grafica, fotográfica, acústica o de cualquier otro tipo, susceptible de recogida, registro, tratamiento o transmisión concerniente a una persona física identificada o identificable." (Martínez Martínez, Ricardo). ${ }^{32}$ El numero $\mathrm{IP}^{33}$ posee la condición de dato de carácter personal, al igual que la dirección de correo electrónico; ambos constituyen una información concerniente a personas físicas identificadas 0 identificables.

El uso de las tecnologías de la información, continúa ilustrando Martínez, R., genera una serie de rastros susceptibles de ser considerados datos personales. Tal naturaleza poseerá un registro de páginas web visitadas, un análisis del tráfico de un determinado terminal, el registro de números telefónicos en una factura o la ubicación espacial de un determinado sujeto obtenida mediante técnicas de localización. El art. 18.4 CE constituye la génesis de este derecho según el cual "la ley limitará el uso de la informática

32 Martínez M, R. (2008). Secreto de las comunicaciones vs. Protección de datos en el ámbito laboral. Pamplona: Aranzadi S.A.

33 El denominado tratamiento invisible de los datos como otra modalidad de Internet gracias al protocolo TCP/IP (Control de Protocolo de Transmisión o Protocolo de Internet), por ocultarle al usuario información, por ejemplo los datos de conexión que identifican el IP, son actualmente de gran uso en el campo del comercio electrónico. En: Rivera, M. del R. (2009). Seguridad Informática y Comunicaciones Electrónicas. Facultad de Ciencias Sociales y Jurídicas de la Universidad Carlos III de Madrid, pág. 4. Manuscrito no publicado. 
para garantizar el honor, la intimidad personal de los ciudadanos y el pleno ejercicio de sus derechos". No por casualidad se ubica en un precepto constitucional que garantiza los derechos fundamentales al honor, a la intimidad y a la propia imagen (art. 18.1), a la inviolabilidad del domicilio (art. 18.1 CE) y al secreto de las comunicaciones (art. 18.3).

Para el Tribunal Europeo de Derechos Humanos (TEDH) el Habeas Data es la facultad de conocer en todo momento qué sabe el Estado sobre nosotros; constituye una garantía del derecho a la vida privada, no obstante establecer límites legítimos como la seguridad del Estado, o la persecución de infracciones penales.

Para el Tribunal Constitucional el objeto de la protección de datos es la garantía del pleno dominio del individuo sobre su identidad personal. No se trata de proteger su intimidad, ni el honor, ya protegidos legalmente, sino garantizar a la persona (nacional o extranjera) un poder de control sobre sus datos personales, sobre su uso y destino, con el propósito de impedir el tráfico ilícito y lesivo para su dignidad y derechos, así como para oponerse a cualquier reconstrucción, conocida o no de su identidad, comportamiento, ideología y opinión a partir de sus datos personales, por parte de quien los posea.

El derecho a la protección de datos consiste en un poder sobre el uso del dato revelado, poniendo a disposición del afectado la facultad de controlar la utilización y destino, prevenir el uso fraudulento o el tráfico ilegal de sus datos personales e incluso, cualquier evaluación de su persona a partir de ellos si la obtención, almacenamiento y tratamiento se ha hecho sin su conocimiento y consentimiento (STC 292/2000; art. 13 LOPD).

El objeto de este derecho fundamental son las informaciones que permitan la identificación de la persona y no el que esa información sea relativa a aspectos de su vida más o menos confidenciales. No debe confundirse el objeto del derecho con su función en el marco de un sistema democrático. El contenido del derecho fundamental a la protección de datos hace referencia al poder jurídico de control sobre los datos, que se concreta en el derecho a estar informado y consentir la recolección, almacenamiento, tratamiento y uso de los datos personales incluida su cesión a terceros, pudiendo oponerse a todo este procedimiento. Igualmente hace referencia al derecho de acceso a dichos datos, a su rectificación o su cancelación; todo esto constituye el contenido esencial de este derecho, según lo establece la STC 292/2000. Respecto a los límites de este derecho la Constitución considera que están referidos al evento en el que se afecte la garantía de los otros derechos fundamentales y constitucionales, en particular los derechos a la intimidad y al honor; a la libertad religiosa e ideológica, a la seguridad y defensa del Estado, a la averiguación y persecución del delito, entre otros aspectos.

\section{EL ENTORNO LABORAL EN LA RELACIÓN DE TRABAJO}

El uso ilegítimo de la informática es una práctica o tendencia que se deja sentir con mayor 
fuerza en el entorno de las relaciones laborales, en razón a que el tratamiento de datos en la gestión del talento humano constituye una práctica cada vez más extendida y en muchos casos imprescindible. Las telecomunicaciones y la informática amplían enormemente la capacidad de acumulación y transmisión de información permitiendo al empleador un conocimiento completo del perfil de sus trabajadores, en el que se incluyen desde aspectos estrictamente profesionales hasta características individuales que rayan en el ámbito de lo privado. Así lo afirma Simitis, S. ${ }^{34}$ “El precio de la computarización es que el trabajador ha llegado a ser vulnerable en un grado impredecible" pues la creación de grandes bancos de datos de los trabajadores, alimentados y utilizados por los empresarios para finalidades "imprecisas, episódicas, incontroladas," aumenta los peligros a los cuales puede quedar expuesta la intimidad o dignidad de éstos en caso de no adoptar las medidas cautelares oportunas. ${ }^{35}$

La automática permite un ilimitado e indiscriminado acarreo de datos personales del empleado, afirma Susana Rodríguez Escanciano agregando que, los riesgos que entraña el poder informático para los derechos de los trabajadores derivan básicamente de su capacidad de recopilar y de transmitir datos sobre su persona, así como de la potencialidad de tratamiento o elaboración de la información recabada. ${ }^{36}$

34 Simitis, S. En Rodríguez E, S. (2009). El derecho a la protección de datos personales de los trabajadores: Nuevas perspectivas. AlbaceteEspaña: Bormarzo.

35 Rodríguez, E. S. Óp. cit., pág. 5.

36 Rodríguez E, S. Óp. cit., pág. 5.
El problema que se aborda ha sido correctamente planteado por Rodríguez Escanciano, cuando manifiesta que la agresividad de la informática frente a los derechos del individuo, en el marco de la relación laboral, busca establecer un punto de equilibrio entre el derecho del empleador (empresario) a optimizar las posibilidades que le ofrecen las nuevas tecnologías, incluidas la organización de la mano de obra y la preservación de los derechos y libertades fundamentales del trabajador, para construir principios y reglas especiales para este sector desde una reglamentación jurídica.

\subsection{Aspectos del entorno laboral}

La relación de trabajo implica dos escenarios perfectamente delimitados y descritos de la siguiente manera: el primero de ellos corresponde al ambiente estrictamente laboral (dentro de la empresa), en el cual el rol que el trabajador desempeña estaría circunscrito a lo que realiza en razón del cumplimento de las funciones laborales, identificado como el escenario trabajador-persona; un segundo escenario haría referencia a la actividad desarrollada por el trabajador por fuera de su ámbito laboral o de la empresa y que corresponde a su interactuar personal, familiar y social, que se identifica como el de persona-trabajador. Al respecto Apilluelo, M. ilustra detalladamente estos dos escenarios como Contornos Personales de la Prestación de Trabajo37, correspondiendo al entorno "trabajador-persona" aquel en que el trabajador debe cumplir la obligación que deriva

\footnotetext{
37 Apilluelo M, M. (2003). Contornos de control empresarial de la intimidad del trabajador ante las nuevas tecnologías y a la luz de la doctrina judicial. Pamplona: Aranzadi social.
} 
de su contrato realizando el trabajo convenido; en tanto persona le pertenecen espacios de intimidad, por ejemplo: conversaciones privadas con otros compañeros, el uso de instalaciones o lugares reservados al descanso o esparcimiento; la utilización privada de medios y materiales dispuestos por la empresa (puestos de trabajo, armarios, escritorio, casillero postal, restaurantes, cafetería y otros espacios de esparcimiento), como también otros medios y materiales de nueva tecnología.

El escenario correspondiente al entorno "persona-trabajador" hace referencia a los espacios de intimidad que son externos a la prestación del servicio, como por ejemplo, el itinerario de llegada al trabajo o el de regreso del mismo, eventos relacionados con incapacidad por enfermedad 0 accidente, absentismo laboral, permisos, descansos, licencias, vacaciones, en fin todas aquellas circunstancias externas a ese núcleo de la prestación laboral, que tienen repercusiones y por lo tanto efectos jurídico-laborales en razón a que su fundamento está ligado con la relación contractual vigente.

Teniendo en cuenta que el empleador es quien tiene la facultad legal para controlar y vigilar el cumplimiento de la prestación de trabajo, puede ejercer también dicho control cuando el trabajador se encuentra por fuera del mismo, al controlar y vigilar, por ejemplo, el trayecto que este ha efectuado para entrar o salir del trabajo (cumplimento de la jornada laboral, incapacidades, comisiones de servicio); su actividad privada en las situaciones de incapacidad médica o permisos retribuidos (buena fe contractual); o su vida privada si repercute en el trabajo (embriaguez, toxicomanía); y otras situaciones derivadas de la relación laboral. Es decir, la consecuencia inmediata es que los derechos de la personalidad del trabajador están expuestos continua y permanentemente en toda la vigencia del contrato de trabajo, teniendo en cuenta no solo el entorno trabajador-persona sino las implicaciones de su vida personal externa a la prestación de su trabajo. Desde esta perspectiva, los procedimientos de control y vigilancia de la actividad profesional del trabajador a través de los actuales medios tecnológicos permiten no sólo llegar (aspecto procedimental) a todo este espacio de privacidad (aspecto cuantitativo) sino también recabar información que extralimita los fines propuestos (aspecto cualitativo).

Si bien es cierto que el trabajador tiene derecho a la inviolabilidad de su persona frente a las injerencias del empresario, debe sin embargo aceptar la modulación de sus derechos personales por la colisión con otros derechos empresariales semejantes. Se hace necesario un equilibrio entre las obligaciones del trabajador derivadas de su contrato de trabajo y el ámbito de su libertad constitucional. El control de su libertad, como derecho fundamental, deberá realizarse en la medida estrictamente imprescindible para su correcto y ordenado respeto, guardando las debidas proporciones y nunca pretender la eliminación de tales derechos ni generar nuevas restricciones, es decir, el ejercicio de las facultades organizativas y disciplinarias del empresario o empleador no pueden lesionar los derechos fundamentales-constitucionales del trabajador. De igual forma, la ausencia de control de 
la actividad profesional del trabajador no puede menoscabar los derechos constitucionales del empleador o empresario.

El trabajador tiene derecho a la intimidad de su trabajo y de su archivo personal, de su correo electrónico e Internet para el cumplimiento de sus funciones laborales o desempeño de las actividades que su cargo le exige, e incluso para uso personal en cuyo caso se identificarán los correos con la palabra "personal". La utilización del ordenador, de Internet y del correo electrónico debe ser acorde con los fines del cumplimiento de las obligaciones laborales, no obstante que su utilización para propósitos particulares con abuso es de todos conocida, bien sea de forma cuantitativa (cadena de mensajes electrónicos privados, mensajes privados con anexos de gran tamaño), cualitativa (juegos de azar, sorteos, subastas, descarga de videos, audio y otros materiales), y hasta con contenidos delictivos (mensajes falsificados, material ofensivo, inapropiado o discriminatorio), situaciones muy frecuentes en empresas en donde no existe una entrada personal que permita la diferenciación, lo que sí ocurre con los teléfonos móviles con doble pin de entrada: profesional y personal. $^{38}$

La utilización de los medios anteriormente mencionados implica un grado de privacidad que escapa del conocimiento de los demás y también del empresario. Para el efecto el trabajador dispondrá de una clave propia de su exclusivo conocimiento y de los jefes de sistemas de la empresa; de no existir constancia convencional de

38 Sempere, N. y San Martín, M. (2002). Nuevas tecnologías y relaciones laborales. Navarra: Aranzadi S.A., pág. 93 y sig. la existencia de esa clave personal, se deduce un abuso manifiesto en la utilización privada por parte del trabajador y hasta un uso fraudulento o ilícito que permite el control por el empleador a través de procedimientos como el denominado registro informático.

\subsection{Procedimientos de control de vigilancia}

Se dispone de normativa que establece que sólo podrá accederse al archivo personal de un trabajador con su autorización o permiso. Los distintos convenios colectivos se orientan al registro directo y auditoría del ordenador en presencia de algún representante de los trabajadores, en horario laboral y con respeto de la dignidad e intimidad del trabajador. Estos acuerdos están conformes con los lineamientos establecidos en el artículo 18 del RDL 1/1995, de 24 de marzo que establece:"39 "Artículo 18. Inviolabilidad de la persona del trabajador. Sólo podrán realizarse registros sobre la persona del trabajador, en sus taquillas y efectos particulares, cuando sean necesarios para la protección del patrimonio empresarial y del de los demás trabajadores de la empresa, dentro del centro de trabajo y en horas de trabajo. En su realización se respetará al máximo la dignidad e intimidad del trabajador y se contará con la asistencia de un representante legal de los trabajadores o, en su ausencia del centro de trabajo, de otro trabajador de la empresa, siempre que ello fuera posible".

39 Martínez F, D. (2002). El poder de control del empresario en la relación laboral. Madrid-España: CES, pág. 87 y ss. En Apilluelo M., M. Óp. cit., Goñi, J. L. (1998). El respeto a la esfera privada del trabajador. Madrid: Civitas, pág. 99 y ss. 
Con respecto al "registro informático" mencionado anteriormente, agrega Apilluelo $\mathrm{M}$. que es importante aclarar que cuando se trate de averiguar la irregularidad del trabajador en el cumplimento de su obligación contractual (tipo de páginas web consultadas, tipo de aplicaciones utilizadas, cantidad de correos enviados, etc.), puede aceptarse la intromisión en contenidos privados si cumple con las demás condiciones de adecuación legal y constitucional. El otorgamiento de la anuencia para el registro y control del ordenador del trabajador en esos estrictos términos no significaría, en modo alguno, renunciar a la libertad de intimidad del trabajador ni sería contrario a la moral y orden público. ${ }^{40}$

El ámbito de la privacidad del trabajador en el control de los sitios web visitados por él durante la jornada de trabajo, se encuentra regulado en el art. 20.3 del ET así: “El empresario podrá adoptar las medidas que estime más oportunas de vigilancia y control para verificar el cumplimiento por el trabajador de sus obligaciones y deberes laborales, guardando en su adopción y aplicación la consideración debida a su dignidad humana...". El citado artículo no hace ninguna referencia a la utilización y manejos de páginas web, lo que permite deducir que tampoco lo prohíbe. Al respecto, la Agencia de Protección de Datos (AEPD) tiene establecido que: “...en principio y de modo general, siempre que el correo electrónico, archivo informático, etc., o cualquier otra comunicación formen parte de la actividad laboral del trabajador y se realicen en tiempo de trabajo pueden ser analizadas y supervisadas por el empresario dado

40 Apilluelo M., M. Óp. cit., pág. 6. que entrarían dentro de la potestad de control que puede ejercer legalmente...".

El Tribunal Superior de Justicia de Cantabria (Sala de lo social), en Sentencia No. 48 de 2007, de 18 de enero, ha establecido que "el hecho de que no se halle vedada la utilización de las nuevas tecnologías entre los instrumentos disponibles para el control y vigilancia de la actividad laboral, no comporta que su aplicación pueda hacerse de manera omnímoda e indiscriminada, con abstracción de los derechos fundamentales del trabajador...".

Así mismo, el art. 8.1 del Convenio Europeo consagra un derecho al respeto de la privacidad, que la jurisprudencia del Tribunal Europeo de Derechos Humanos ha determinado que no se limita al hogar, sino que se aplica también al lugar de trabajo.

\subsection{Deber de la buena fe contractual}

Respecto a las medidas disciplinarias adoptadas por las empresas con base en presuntas irregularidades laborales relacionadas con las nuevas tecnologías, y dada la ausencia de previsiones específicas en los convenios colectivos, es necesario recurrir a la doctrina acerca del deber de buena fe y sus dimensiones.

La buena fe es una exigencia que ha de caracterizar toda relación contractual y ningún derecho, ni siquiera los considerados fundamentales por la Constitución española, puede ejercitarse faltando a este principio, el cual ha sido definido por el Tribunal Supremo en Sentencia de 20 de noviembre de 1989, como “...un principio 
general de derecho que impone un comportamiento ajustado a valoraciones éticas, que condiciona y limita por ello el ejercicio de los derechos subjetivos, con lo que en principio se convierte en un criterio de valoración de conductas, con el que deben cumplirse las obligaciones, $y$ que se traduce en directivas equivalentes a lealtad, honorabilidad, probidad y confianza..."

En Sentencia del TSJ de la Comunidad Valenciana (Sala de lo Social), núm. 107/2001 de 11 enero, se establece que: "Ia BUENA FE es consustancial al contrato de trabajo, pues su naturaleza genera derechos y obligaciones reciprocos, que se traducen en una exigencia de comportamiento ético, acorde a una serie de valoraciones objetivas, que limita o condiciona el ejercicio de los derechos subjetivos, y que se concreta en valores que pueden traducirse por lealtad, honorabilidad, probidad y confianza; que la esencia de su incumplimiento no está en la causación de un daño, sino en el quebranto de los anteriores valores, por lo que, a pesar de la inexistencia de perjuicio alguno a la empresa, a pesar de ser un elemento a considerar y ponderar en orden a su gravedad, no se enerva la transgresión, para cuya consideración también deben valorarse las condiciones personales $y$ profesionales del trabajador y la confianza depositada en el mismo...".

Por lo tanto, y en razón a la buena fe, no se admite que se exija y controle al trabajador en todo momento, pues una conducta impecable sin el menor descuido o una diligencia celosa y sin desfallecimiento, así como el deber de mutua fidelidad entre empresario y trabajador implica cierto margen de libertad necesario para el desarrollo de la actividad laboral que debe ser utilizado para conseguir los fines y objetivos de la empresa. Por lo anterior, el uso adecuado de las nuevas tecnologías por parte del trabajador que no extralimite este margen de libertad personal permitido, caracteriza el ejercicio legítimo de este principio dentro de la empresa no pudiendo por tanto ser sancionado por ello. Recíprocamente, este deber mutuo de buena fe se predica del empresario que puede acceder a información privada del trabajador a través de la nueva tecnología, obligándolo a que la información así obtenida no pueda ser utilizada en contra del trabajador, así como a guardar el secreto de la misma y a prohibir su divulgación sin el consentimiento del mismo. Esto constituye un impedimento para instalar medios tecnológicos de vigilancia en vestuarios, baños, lugares de descanso o esparcimiento, comedores o análogos, porque son lugares privados donde no se da la prestación del trabajo en sentido estricto y resultarían lesivos del derecho a la intimidad personal y dignidad del trabajador.

En conclusión, se puede afirmar que frente a las diversas conductas irregulares del trabajador por utilización del correo electrónico para fines particulares, visitas a páginas informáticas ajenas a la actividad laboral, acceso indebido a informaciones reservadas, etc., las empresas recurren a medidas extremas como el despido interpretando la jurisprudencia al respecto, para la cual la transgresión de la buena fe se entiende cometida aunque no se acompañe de lucro personal ni de haber causado daños a la empresa. Es necesario destacar que el daño o 
perjuicio patrimonial causado a la empresa es factor fundamental en la ponderación de la gravedad de la transgresión. De la misma manera, vale advertir que si no es evidente un incumplimiento contractual grave (relevante y trascendente) y culpable (doloso o negligente de manera inexcusable), tampoco puede existir despido procedente. Es recomendable el análisis de todas las circunstancias (objetivas y subjetivas) antes de proceder a sancionar irregularidades conectadas con el uso de medios tecnológicos, para examinar si es o no procedente el despido y evitar exageraciones, abusos o extralimitaciones frente a conductas, como por ejemplo: remitir un mensaje de correo electrónico extralaboral que conlleve un proceder y medidas inapropiadas o desproporcionadas.

\section{PRINCIPIOS QUE DIRECCIONAN LA ACTUACIÓN FRENTE A LA PROTECCIÓN DE DATOS}

La salvaguarda de la vida privada del trabajador o trabajadora afecta tanto el vínculo de subordinación que caracteriza el contrato de trabajo como la libertad de hombres y mujeres de una sociedad democrática, de ahí que sea necesario intervenir en la protección de los derechos del trabajador y ciudadano. Para la empresa, la apertura al mundo gracias a Internet y a la utilización de redes de información, la hacen vulnerable a los ataques informáticos externos; las medidas de seguridad entonces constituyen una necesidad para evitar intrusiones y para proteger los documentos confidenciales. Estas medidas de seguridad Ilevan incorporada la trazabilidad directa o indirectamente nominativa en los tratamientos de la información a fin de protegerla de los riesgos y localizar el origen de la interferencia. Es importante entonces que los trabajadores tengan conocimiento de las posibilidades de este seguimiento o trazabilidad, especialmente por acumulación o comprobación de huellas múltiples, que las nuevas tecnologías ofrecen al empleador. En consecuencia el equilibrio necesario entre el control legítimo ejercido por la empresa y el respeto a los derechos de los trabajadores no parece asegurado en tanto nos encontremos sin respuesta frente a cuestionamientos como los que plantea Hubert Bouchet:

“¿Cuál es la parte de la vida privada y de las libertades individuales garantizadas a los asalariados que están ligados al empleador por un contrato de trabajo como primer vínculo de subordinación?

¿Cuál es el uso admitido para fines privados de las herramientas puestas a disposición de los asalariados por su empleador?

¿Hay límites al control y a la vigilancia que los empleadores pueden ejercer sobre los asalariados?"

Al respecto, la LOPD busca garantizar la tutela de los derechos que puedan resultar afectados por la potencialidad lesiva de la información aplicada al tratamiento de los datos personales, estableciendo principios desarrollados en el Real Decreto (RD) 1720/2007 de 21 de diciembre y son: 
5.1 Consentimiento informado (art. 12 RD 1720/2007)

Inherente al derecho de Autodeterminación Informativa del afectado, le otorga la facultad de asegurar un nivel mínimo de protección de los datos a él referidos, a través de la exigencia del consentimiento informado e inequívoco para la licitud de la información solicitada. Como regla general, el interesado o afectado ha de prestar su consentimiento ${ }^{41}$ para recoger y tratar sus datos personales (art. 6 y 11 LOPD) y el responsable del tratamiento deberá informarle del objeto y finalidad de esas operaciones (art. 5 LOPD). La información previa ${ }^{42}$, referida al consentimiento informado, impone según algunos tratadistas la obligación de informar a las personas que les concierna, especialmente a los destinatarios de los datos, y el lugar donde se ejerce el derecho de acceso y rectificación. Prohíbe que los datos sean recogidos por un medio fraudulento, desleal o ilícito; y obliga a la transparencia en su manejo y utilización. Así entonces, el consentimiento informado del afectado es un requisito legal sine qua non para el acopio, utilización, cesión, conservación y tratamiento automatizado de los datos personales del trabajador. El consentimiento informado, como principio regulador de las relaciones empresario-trabajador

41 Concepto legal de consentimiento, de acuerdo con el art. 3 LOPD "Toda manifestación de voluntad, libre, inequívoca, específica (o informada), mediante la cual el interesado (persona física, titular de los datos), consciente el tratamiento (operaciones y procedimientos técnicos de carácter automatizado o no, que permitan la recogida, grabación, conservación, elaboración, modificación, bloqueo y cancelación, así como las cesiones de datos que resulten de comunicaciones, consultas, interconexiones y transferencias), de datos personales (cualquier información concerniente a personas físicas identificadas o identificables), que le conciernan”. En Tascón, R. (2005). El tratamiento por la empresa de los datos personales de los trabajadores. Análisis del estado de la cuestión. $1^{\mathrm{a}}$ ed. España: Navarra, pág. 106.

Farriols, S. Óp. cit., pág. 173 y ss en la protección de datos de carácter laboral, se caracteriza por una unión inescindible entre dos requisitos: consentir e informar. El deber de informar con transparencia tiene como finalidad la comunicación inter-partes de las condiciones y alcance de los compromisos que adquiere con el tratamiento de los datos que se acopian. El art. 5 LOPD enumera aquellos aspectos que deberán ser informados así:

- De la existencia de ficheros o bases de datos, tratamiento, finalidad y destinatarios de la información.

- De las consecuencias de la obtención de los datos o de la negativa a suministrarlos.

- De la identidad y dirección del responsable del tratamiento o su representante.

Establece la ley igualmente que si se utilizan cuestionarios o impresos para recoger información deben figurar en ellos de manera clara y legible las advertencias indicadas.

\subsection{Pertinencia y proporcionalidad}

Consecuente con la relación laboral se genera una interacción de derechos de los trabajadores y de su empleador, lo que conduce a establecer criterios de equilibrio y ponderación que se han denominado principio de proporcionalidad, en virtud del cual toda medida restrictiva de derechos fundamentales (por ejemplo la intimidad) ha de ser idónea, necesaria y proporcional en sentido estricto. Al respecto se cita a Sempere 
N. y San Martín, M. ${ }^{43}$, quienes afirman que la idoneidad se cumple si la medida es susceptible de conseguir la finalidad pretendida (hace referencia al medio utilizado para conocer la conducta laboral de los empleados); la necesidad de la medida se traduce en que la misma ha de revelarse como indispensable para el correcto y ordenado desenvolvimiento de la actividad productiva, al no existir otra acción más moderada que permita conseguir idéntico propósito con el mismo grado de eficacia (STC 98/2000, de 10 de abril); y la proporcionalidad se alcanza si la medida es ponderada, equilibrada y respeta el contenido esencial de los derechos fundamentales. La medida restrictiva de derechos también debe estar suficientemente justificada, esto significa que su adopción ha de responder a motivaciones objetivas, distintas de la conveniencia o capricho empresarial. Según lo afirma Rodríguez E. ${ }^{44}$ la información por vía informática que se pretende recabar o acumular ha de ser adecuada y proporcional (art. 4.1 LOPD), esto es, no solo debe ser legítima sino adecuada a la finalidad pretendida (en lógica, exigencia de congruencia) y proporcionada, entendiendo por tal un nivel de recogida y almacenamiento de datos "no excesivo" respecto de dicha finalidad (art. 8.4 RD 1720/2007).

La proporcionalidad es un principio que implica la complejidad de distinguir entre lo que compete a la vida profesional y lo que pertenece a la intimidad de la vida privada. El propósito es

43 Sempere, N. y San Martín, M. (2002). Sobre nuevas tecnologías y relaciones laborales. Pamplona: Aranzadi S.A.

44 Rodríguez E, S. (2009). El Derecho a la protección de datos de los trabajadores: Nuevas perspectivas. Albacete-España: Bomarzo, pág 2 . asegurar el buen funcionamiento del servicio informático, la seguridad digital de la empresa o el confort del usuario. La trazabilidad ligada a todo ello está referida a las actuales tecnologías de la información y comunicación (TIC). Por lo tanto, no es su existencia sino su tratamiento con otros fines distintos a los técnicos, lo que debe ser proporcional al propósito buscado. Agrega igualmente Rodríguez E., que la ausencia de mayor precisión legal y de jurisprudencia consolidada a este respecto no impide colegir cuáles serán los parámetros generales para medir la pertinencia y proporcionalidad de los datos informáticos requeridos o acumulados. En la fase de selección de personal será prohibido recoger aquellos datos no estrictamente necesarios para llevar a cabo la valoración de la capacidad profesional del candidato, siendo "excesiva" (y en consecuencia prohibida) cualquier otra averiguación sobre hechos no imprescindibles para su determinación, por constituir un abuso en el proceso de obtención de datos del trabajador. Respecto a la recolección y acumulación de datos informáticos durante la vida laboral del trabajador es clara la exigencia de que obedezcan a efectivas y reales necesidades organizativas, productivas o de seguridad en el trabajo, es decir, a un interés empresarial serio y por tanto legítimo, siempre y cuando no constituya un abuso o invasión justificada en la esfera privada del individuo. ${ }^{45}$

Es importante precisar el fin y utilizar los datos personales de conformidad con él. Para el caso de solicitudes de trabajo o de empleo la

45 Tascón, R. (2005). La protección de datos personales de los trabajadores. En Rodríguez E, S. Óp. cit., pág. 22 y ss. 
extinción de dicho fin o la imposibilidad de su materialización hacen necesaria su destrucción. El principio de proporcionalidad excluye, entonces, el control general de los mensajes electrónicos y de la utilización de Internet de todo el personal, salvo si resulta necesario para garantizar la seguridad del sistema. En el evento en que sea forzosa una intromisión en la vida privada de los trabajadores, el empleador deberá considerar su aplicación; así por ejemplo evitará sistemas de vigilancia automática y continua. Con referencia al correo electrónico deberá limitarse a los datos sobre tráfico de los participantes y la hora de comunicación más que su contenido. Si el acceso al contenido de los mensajes es indispensable, es necesario tener en cuenta el respeto por la vida privada de los destinatarios externos e internos de la organización; así entonces, el empleador no puede obtener consentimiento de personas ajenas a la empresa que envían mensajes a los miembros de su personal. Del mismo modo, el empleador deberá aplicar todos los medios razonables para informar a las personas ajenas a la organización de la existencia de actividades de vigilancia que pudieran afectarlas.

La tecnología ofrece al empleador importantes posibilidades de evaluar la utilización del correo electrónico por parte de sus trabajadores, comprobando, por ejemplo, el número de mensajes enviados y recibidos o el formato de los documentos adjuntos, situación que podría considerarse desproporcionada. La tecnología puede también usarse para garantizar que sean proporcionadas las medidas adoptadas por el empleador para proteger de todo abuso el acceso a
Internet autorizado a su persona, aplicando mecanismos de bloqueo más que de vigilancia. En lo referente a la cuestión de la proporcionalidad debe destacarse que el mecanismo de negociación colectiva puede resultar muy útil para decidir qué acciones son proporcionadas al riesgo que corre el empleador. Es posible alcanzar un acuerdo entre el empleador y los trabajadores sobre la forma de conciliar los intereses de ambas partes, como lo sugiere Cardenal C., M. ${ }^{46}$

\subsection{Congruencia, finalidad y racionalidad}

Desde una perspectiva laboral, y atendiendo a la dinámica jurídico-comercial de las empresas, se hace necesario el uso de las más variadas informaciones. La finalidad, entonces, es tratar aquella información verdaderamente necesaria para atender los legítimos propósitos de una sociedad democrática; deben hacerlo, además, las personas adecuadas y conforme a procedimientos preestablecidos legalmente para garantía de su licitud y para que el sujeto afectado por el tratamiento de datos pueda tener conocimiento y acceso a la información en cuestión. Este principio implica la existencia de un motivo justificado y legítimo para la recolección y clasificación de los datos de carácter personal. Es decir, se trata de una exigencia para las partes de actuar de buena fe, evitando todo tipo de actuaciones engañosas y estableciendo los límites entre la licitud e ilicitud. Así lo establece el art. 4.1 LOPD: “Los datos de carácter personal sólo se podrán recoger para su tratamiento, así

46 Cardenal C, M. (2004). El abuso de Internet en el trabajo ¿vamos bien? Pamplona: Aranzadi S.A. 
como someterlos a dicho tratamiento, cuando sean adecuados, pertinentes y no excesivos en relación con el ámbito y las finalidades determinadas, explícitas y legítimas para las que se hayan obtenido".

El art. 4, párrafo 3, de la LOPD establece que los datos sean exactos y actualizados y que respondan a la situación real del afectado, y obliga al responsable del manejo de los mismos (el empleador-empresario) a cancelar de oficio aquellos datos total o parcialmente inexactos o incompletos y a sustituirlos por datos rectificados, esto es, actualizados, pues una información desactualizada puede ser considerada inexacta o incompleta. Cabe agregar que el empresario debe especificar un periodo de conservación en función de las necesidades profesionales, y hay consenso en que el mismo no debe superar los tres meses ${ }^{47}$ por ejemplo, para conservación de mensajes electrónicos en sus servidores centrales. Es necesario igualmente aplicar medidas técnicas y organizativas adecuadas para la SEGURIDAD de los datos personales recabados; esto implica proteger su sistema contra virus, lo cual conlleva el análisis automatizado de los mensajes electrónicos y de los datos relativos al tráfico en la red. Es fundamental que toda persona que tenga acceso a datos personales de los trabajadores, esté sometida a una obligación estricta de secreto profesional respecto a la información confidencial que pueda conocer. ${ }^{48}$

Los arts. 4.5 LOPD y 8.6 RD 1720/2007 aluden al almacenamiento, cancelación y descontextualización de los datos informáticos, es decir, que la duración y mantenimiento de los datos no puede ser ilimitada y tienen como condición que una vez se satisfaga la finalidad concreta, en virtud de la cual fueron recogidos y registrados, deben ser cancelados. Ahora bien, si por razones o consideraciones estadísticas, históricas o científicas, debidamente justificadas, debieran ser conservados, entonces se hace necesario eliminar la posibilidad de identificar al interesado. La finalidad esgrimida determina, en consecuencia, el periodo máximo durante el cual serán almacenados los datos, es decir, el estrictamente imprescindible. En el evento de que el trabajador cambie de empresa por terminación del contrato de trabajo, por voluntad propia o por haber sido cesado por el empresario, o cuando concluido el proceso de selección el solicitante de empleo no haya sido aceptado, desaparece el fin para el cual fueron recabados los datos; en tal situación carecerá de sentido mantener tales informaciones por parte del empresario. En este sentido el art. 16 LOPD establece que el empresario incurre en un ilícito cuando mantiene datos del trabajador más allá del término de la relación laboral e incluso si se los oculta al propio trabajador para utilizarlos luego en actuaciones en su contra. No obstante, es preciso entender que si los datos recabados con ocasión del proceso de selección siguen siendo útiles al empresario para la dirección y organización de la prestación laboral en la empresa (fin indudablemente legítimo) y, por tanto, adecuados, pertinentes y no excesivos deberá ser admitido su tratamiento informático.

$47 \quad$ Cardenal C, M. Óp. cit., pág. 11.

48 Cardenal C, M. Óp. cit., pág. 12. 
5.4 Negociación colectiva

Como principio básico en la protección de los datos laborales, se traduce en que las organizaciones sindicales deben ser informadas y consultadas previamente de las decisiones empresariales que tengan relación con los medios o las técnicas que constituyan un control a la actividad de los trabajadores, e implica que las condiciones de trabajo del personal deben ser transmitidas para información y consulta. Los diferentes agentes sociales, técnicos, científicos, investigadores, juristas, sindicatos o empresarios, desempeñan un papel importante frente al desarrollo tecnológico y su uso respetuoso de los derechos fundamentales. Estos deben ser capaces de identificar los bienes jurídicos concernidos y fijar criterios de solución ante situaciones de conflicto donde prevalecen mayoritariamente los de índole jurídica, por lo que se sugiere: ${ }^{49}$

"Identificación específica de los derechos afectados por los controles empresariales y la intensidad de los mismos. Conductas exigibles al empresario en cuanto a la adopción de controles. Establecimiento de supuestos en los que los controles deban exigirse o resulten necesarios. Valor y/o jerarquía de las normas que deben regular este tipo de conflictos. Grado de coercibilidad y validez de los documentos que impliquen obligaciones relativas a las tecnologías de la información, renuncias a derechos y del consentimiento otorgado por el trabajador cuando las acepta. Uso sindical de medios informáticos.

49 Martínez M, R. (2008). Secreto de las comunicaciones vs. protección de datos en el ámbito laboral. Pamplona: Aranzadi S.A.
Papel garante de los representantes de los trabajadores en el establecimiento de medios de control. Fijación de políticas de uso, respetuosas con los derechos fundamentales. Capacitación de los usuarios de las tecnologías de la información, sean estos responsables corporativos o trabajadores...". El Comité de empresa o los representantes sindicales que acceden a la información de los trabajadores están obligados a guardar secreto y al cumplimiento de los principios de la LOPD y de los específicamente previstos en las normas que les sean de aplicación.

Todo lo anterior comporta que la negociación colectiva debe desempeñar un papel fundamental en la ordenación del uso de tecnologías de la información en el entorno laboral, y en la búsqueda de soluciones no sólo respetuosas de los derechos fundamentales sino también prácticas y funcionales. Es importante destacar que el derecho a la libertad sindical ha de prevalecer sobre el derecho a la protección de datos personales. La acción sindical ampara la actuación del sindicato para divulgar entre los trabajadores los datos precisos y necesarios para el entendimiento de la noticia, con base en un conocimiento cierto de la información relevante desde la perspectiva sindical SAN (Sentencia de la Audiencia Nacional), de 19 de diciembre de 2007. El ET comprende una serie de facultades otorgadas a los representantes sindicales y en particular al Comité de empresa, que en algunos casos pueden comportar el acceso a datos; por ejemplo, conforme al art. 64 del ET, el Comité de empresa tendrá derecho a ser informado de todas las sanciones impuestas por faltas muy graves, como también a recibir copia básica de los 
contratos, notificación de prórrogas y denuncias correspondientes a los mismos, en el plazo de diez días siguientes a que tuvieran lugar, todo ello amparado en las condiciones exigidas por el principio de protección de datos de carácter personal.

INCIDENCIA DE LAS NUEVAS TECNOLOGÍAS DE LA INFORMACIÓN Y COMUNICACIÓN (TIC) Y EL CONTROL EMPRESARIAL

La generalización de las nuevas tecnologías de la información y las comunicaciones ha propiciado un nuevo modelo de trabajador, más formado, más cualificado, más flexible y como dice Castells, "autoprogramable". Se trata de un trabajador más autónomo en la ejecución de sus tareas y con mayor grado de responsabilidad, que aporta al proceso de producción, además del trabajo, su propia imaginación y creatividad. Este valor agregado es el que le hace irremplazable y confiere a la empresa un factor clave de competitividad que no puede obtenerse sacrificando los derechos de los trabajadores, sino apostando por la excelencia y la calidad empresarial con un modelo de trabajador como el descrito anteriormente, pues no nos hará ser más competitivos tener condiciones de trabajo de bajo coste, sino aspirar a que todas las empresas estén altamente tecnificadas y todos los trabajadores altamente formados en la aplicación de la tecnología. La generalización de las tecnologías de la información y la comunicación, y su aplicación al proceso productivo, va a afectar el desarrollo de las relaciones de trabajo que necesariamente deben ser objeto de revisión a fin de evitar que las ventajas de las nuevas tecnologías no queden oscurecidas y empañadas por efectos no deseados ${ }^{50}$.

El ET ha atribuido facultades específicas a la empresa con el propósito de hacer control al desarrollo de la prestación laboral. La aplicación de las TIC se manifiesta de muy diversos modos; pueden citarse entre otros, los controles biométricos como la huella digital, la video vigilancia, los controles sobre el ordenador (como revisiones, el análisis o la monitorización remota, la indexación de la navegación por internet, la revisión y monitorización del correo electrónico y/o del uso de ordenadores), controles sobre la ubicación física del trabajador mediante geolocalización. ${ }^{51}$

En efecto, la celebración del contrato de trabajo otorga al empresario-empleador un poder de dirección del cual deriva, a su vez, un poder de control para adoptar las medidas tendientes a verificar el cumplimiento de las obligaciones y deberes laborales de los trabajadores, para lo cual instala complejos mecanismos cuyas manifestaciones más frecuentes estarían relacionadas con: sistemas de captación de imágenes y sonidos mediante cámaras de video que los visualizan mientras desarrollan su prestación en tiempo y lugar de trabajo; sistemas de verificación de acceso y localización en la empresa (edificios inteligentes) cuyos mecanismos

50 Farriols, S. (2006). La protección de datos de carácter personal en los centros de trabajo. Madrid: Cinca S.A.

51 Agencia Española de Protección de Datos. Guía, La protección de datos en las relaciones laborales. 16 de noviembre de 2009. 11:00H. Disponible en: www.agpd.es. 
facilitan al empleador información que le permite un conocimiento bastante exacto de cuanto en ellos ocurre. Estos sistemas de control incorporan los antes mencionados datos biométricos de los trabajadores (huellas dactilares, registros de voz, iris o retina), que quedan combinados con los sistemas de acceso a los lugares de trabajo y permiten la verificación de quién efectivamente entra o sale de la fábrica u oficina, y aún fuera de ella mediante los sistemas de posicionamiento global (GPS) del trabajador cuando realiza su tarea por fuera de la organización productiva. Controles sobre el correo electrónico (email) puesto por la empresa a disposición del trabajador (muy frecuente por las ventajas de un sistema que facilita una comunicación económica y eficaz con cualquier lugar del mundo). Controles sobre las páginas web visitadas por el trabajador e Internet. Controles para verificar la utilización del PC que el trabajador usa como herramienta de trabajo (posibilitan conocer las páginas web visitadas, programas utilizados, contenidos de los archivos abiertos, tiempo durante el cual el equipo ha permanecido apagado o suspendido) permitiendo una vigilancia total del trabajador. Controles sobre el uso del teléfono (para conocer la frecuencia de las llamadas, número de destino, fecha, hora, duración e incluso el contenido de las conversaciones).

\section{CONCLUSIONES}

El derecho a la protección de datos es un derecho esencialmente de prestación cuyo objeto son los datos que permiten identificar a una persona; su propósito es que esa persona sepa, consienta y pueda disponer en todo momento sobre la publicidad de sus datos y su alcance. Es preciso diferenciar el derecho a la privacidad como aquel que protege el dato antes de ser conocido; por el contrario, el derecho fundamental a la protección de datos lo hace una vez se revelan a un tercero. El primero asegura el dato frente a la curiosidad ajena dotando a la persona del poder jurídico de disponer sobre su accesibilidad a un tercero; el segundo otorga el poder de controlar su uso por ese tercero una vez que el dato le ha sido revelado. El derecho fundamental a la protección de datos no es un derecho de configuración legal, porque su contenido ya ha sido definido en el art. 18.4 de la CE y es de aplicación directa sin necesidad de que medie norma legal alguna que lo concrete. Este derecho ha sido elevado al más alto rango jurídico de protección de la persona frente al conocimiento y uso no consentido, desconocido, no autorizado, fraudulento y abusivo de la información.

La protección de los datos de carácter personal es necesariamente más compleja, cuanto mayor sea la difusión de los datos a niveles nunca vistos en la sociedad de la información y el conocimiento. Ello exige su caracterización como derecho fundamental y su delimitación deberá respetar el principio de legalidad. Este es, sin duda alguna, uno de los derechos fundamentales que más relevancia ha venido adquiriendo en los últimos tiempos, y que mayor desarrollo legal y práctico ha necesitado frente a la aparición de las nuevas tecnologías de la información y la comunicación (TIC) y ante el masivo control y manejo de datos de carácter personal en la 
sociedad actual. El derecho al trabajo y el derecho a la intimidad parecen constituir los derechos a los que converge lo fundamental en la protección de datos de carácter personal en la empresa y el contrato de trabajo. Existe consenso al afirmar que el art. 18.4 de la Constitución debe ser más operativo y que en España no existe aún una cultura suficiente para el tratamiento de este problema: el de la protección de datos en el entorno laboral.

La protección de datos de carácter personal ha sido incluida en el ámbito de la protección de los derechos fundamentales y tiene un gran soporte y fundamento en la jurisprudencia constitucional, lo que prueba la presencia de un derecho fundamental en conexidad con la protección a la intimidad personal y familiar, y un elemento esencial en el derecho a la no discriminación. Los derechos de la personalidad del trabajador están expuestos continua y permanentemente en toda la vigencia del contrato de trabajo y afectan no solo al trabajador como persona en su entorno laboral sino también a la persona del trabajador en su entorno familiar en el escenario externo a la prestación de su trabajo. El derecho a la intimidad no es absoluto al igual que ninguno de los otros derechos fundamentales; en consecuencia se genera una colisión o conflicto con los derechos constitucionales del empresario en razón a su facultad de control y dirección del trabajador para efectos de la actividad productiva empresarial, sus propósitos y objetivos. Esta situación hace necesario deslindar los aspectos de privacidad absolutamente intocables, de aquellos otros que sí pueden serlo por determinadas causas, medida y procedimiento, de acuerdo con el principio de proporcionalidad proclamado constitucionalmente. Ni la ley ordinaria, ni el convenio colectivo, ni el otorgamiento del consentimiento del trabajador de forma individual o colectiva, evitarán que cualquier restricción al derecho a la intimidad del trabajador quede sometida al principio de proporcionalidad.

Es importante destacar que la protección de datos de carácter personal, que instrumenta la LOPD fundamentada en los principios de congruencia, finalidad, racionalidad y consentimiento o autodeterminación, que algunos autores han considerado "MACROPRINCIPIOS" tienen implícitos otros preceptos que derivan de ellos como: PERTINENCIA, es decir, que la recolección y tratamiento de datos sólo es posible cuando los mismos sean adecuados, pertinentes y no excesivos en relación con el ámbito y las finalidades determinadas, explícitas y legítimas para las que se hayan obtenido; FINALIDAD, esto es, que los datos tratados no pueden ser utilizados para propósitos incompatibles con aquellos para los que hubiesen sido recogidos; LEGALIDAD, hace referencia a que el procedimiento no puede adelantarse por medios fraudulentos, desleales, o ilícitos; VERACIDAD Y ACTUALIZACIÓN, significa que los datos serán exactos y deberán estar al día con la situación real del afectado, de manera que se garantice la verdad de los mismos; por lo tanto, los que sean inexactos o incompletos deberán ser cancelados y debidamente sustituidos; ACCESIBILIDAD en cuanto a que el almacenamiento de los datos solicitados al trabajador debe permitirle el ejercicio del derecho de acceso a los mismos; 
CANCELACIÓN Y DESCONTEXTUALIZACIÓN, es decir, los datos serán eliminados cuando hayan dejado de ser necesarios o pertinentes para la finalidad que justificó su recolección.

\section{Bibliografía}

Arias, A. y Rubio, F. (2006). El derecho de los trabajadores a la intimidad. $1^{a}$ ed. Navarra: Aranzadi S.A.

Apilluelo, M. (2003). Contornos de control empresarial de la intimidad del trabajador ante las nuevas tecnologías y a la luz de la doctrina judicial. Pamplona: Aranzadi S.A.

Blasco, C. (2009). Incidencias de las nuevas tecnologías de la información y la comunicación (tic) en las reestructuraciones de las empresas. Pamplona: Aranzadi S.A.

Cano, Y. (2000). El difícil equilibrio entre el derecho a la intimidad y la libertad de empresa. Pamplona: Aranzadi S.A.

Cardenal, M. (2004). El abuso de internet en el trabajo ¿vamos bien? Pamplona: Aranzadi S.A.

Farriols, S. (2006). La protección de datos de carácter personal en los centros de trabajo. Madrid: Cinca S.A.

Luján, J. (2003). Protección de datos de carácter personal y contrato de trabajo. Pamplona: Aranzadi S.A.
Manteca, V. (2008). Control del empresario sobre el uso del ordenador por los trabajadores: alcance, contenido y límites. Pamplona: Aranzadi S.A.

Martínez, R. (2008). Secreto de las comunicaciones vs. protección de los datos en el ámbito laboral. Pamplona: Aranzadi S.A.

Pulido, M. (2000). ¿Numerus clausus o numerus apertus en materia de derechos fundamentales? el derecho fundamental a la protección de datos. Pamplona: Aranzadi S.A.

Quintanilla, R. (2006). Ejercicio de buena fe de los derechos fundamentales en el seno del contrato de trabajo. Pamplona: Aranzadi S.A.

Rivera, M. del R. (2009). Seguridad informática y comunicaciones electrónicas. Facultad de Ciencias Sociales y Jurídicas, Universidad Carlos III de Madrid. Madrid.

Rodríguez de las Heras, B. T. (2008). Legal Framework for Personalization-Based Business Models. In: Personalization of Interactive Multimedia Services: a Research and Development Perspective -CB. José J. Pazos-Arias y Martín López Nores (editors). Madrid: Nova Science Publishers Inc.

Rodríguez, S. (2009). El derecho a la protección de datos personales de los trabajadores: Nuevas perspectivas. ( $1^{\mathrm{a}}$ ed.). AlbaceteEspaña): Bomarzo S.L.

Roldán, A. (2008). El derecho de los representantes de los trabajadores a utilizar los 
medios electrónicos de comunicación propiedad de la empresa (aplicación por los tribunales de la STC 281/2005). Pamplona: Aranzadi S.A.

Sanz, A. (2005). El derecho a la intimidad de los trabajadores. Pamplona: Aranzadi S.A.

Sempere, A. (2002). Sobre "nuevas tecnologías" y relaciones laborales. Pamplona: Aranzadi S.A.
Tascón, R. (2005). El tratamiento por la empresa de datos personales de los trabajadores. Análisis del estado de la cuestión. ( $1^{\mathrm{a}}$ ed.). Navarra: Aranzadi S.A.

Val, J. (2007). Protección de datos de los trabajadores y abandono de documentos por la empresa. Pamplona: Aranzadi S.A.

www.westlaw.es. Derechos y deberes. Derechos fundamentales en la relación de trabajo. La protección de datos de carácter personal en la relación de trabajo. Agencia Española de Protección de Datos. Guía. La protección de datos en las relaciones laborales. Madrid, 2009 